\title{
Basal Forebrain Lesions in Monkeys Disrupt Attention but Not Learning and Memory
}

\author{
Mary Lou Voytko, ${ }^{1,5,6}$ David S. Olton, ${ }^{6}$ Russell T. Richardson, ${ }^{3}$ Linda K. Gorman, ${ }^{6}$ Joseph R. Tobin, ${ }^{2}$ and Donald \\ L. Price ${ }^{1,3,4,5}$
}

Departments of ${ }^{P}$ Pathology, ${ }^{2}$ Anesthesiology and Critical Care Medicine, ${ }^{3}$ Neurology, and ${ }^{4}$ Neuroscience, and ${ }^{5}$ the Neuropathology Laboratory, The Johns Hopkins University School of Medicine, Baltimore, Maryland 21205-2196, and

${ }^{6}$ Department of Psychology, The Johns Hopkins University, Baltimore, Maryland 21218

\begin{abstract}
Cognitive impairments in humans and animals have been linked to dysfunction of neurons in the basal forebrain cholinergic system (BFCS). Degeneration of these cells may be, in part, responsible for some of the cognitive deficits observed in Alzheimer's disease (AD). Although memory deficits are associated with lesions of the BFCS in rats, impairments in memory have been more subtle following similar lesions in monkeys. To evaluate the effects of BFCS lesions on cognitive processes in monkeys, we have systematically investigated the behavioral effects of ibotenic acid injections in the medial septum, nucleus of the diagonal band of Broca, and nucleus basalis of Meynert in cynomolgus monkeys, using a large series of cognitive tasks that examined different mnemonic and attentional abilities. These lesions did not impair accuracy in delayed nonmatching-to-sample, delayed response, simple or concurrent visual discriminations, spatial discriminations, or discrimination reversals. However, these lesions disrupted attentional focusing. Similar impairments in attention have been noted in patients with $A D$. BFCS lesions increased sensitivity to injections of the cholinergic antagonist scopolamine in a delayed nonmatchingto-sample task, indicating that the central cholinergic system was compromised in these monkeys. In concert, the results of this study suggest that the primate basal forebrain may be more involved in attentional than mnemonic processes, and that degeneration of neurons in the BFCS in cases of AD may contribute to the attention deficits observed in these individuals.
\end{abstract}

[Key words: basal forebrain, cholinergic system, attention, learning, memory, monkeys, ibotenic acid, medial septum, nucleus basalis of Meynert, nucleus of the diagonal band of Broca]

\footnotetext{
Received Apr. 22, 1993; revised July 13, 1993; accepted July 15, 1993.

We extend our appreciation to Drs. Lary C. Walker and Molly V. Wagster for helpful discussions, Sharon Dlubala for her indispensable technical assistance in running the experiments, Sandra Sauer and Lance Rowland for their outstanding surgical and postoperative contributions, Dr. Nick Bryan of Neuroradiology for his assistance in refining the MRI protocol, and Dr. Steven Breckler for his statistical expertise. This work was supported by grants from the U.S. Public Health Service (NIH NS 20471), as well as the American Health Assistance Foundation and the Metropolitan Life Foundation. D.L.P. is the recipient of a Leadership and Excellence in Alzheimer's Disease (LEAD) Award (AC 07914) and a Javits Neuroscience Investigator Award (NS 10580).

Correspondence should be addressed to Dr. Mary Lou Voytko, Department of Comparative Medicine, Bowman Gray School of Medicine, Medical Center Boulevard, Winston-Salem, North Carolina 27157-1040.

Copyright (C) 1994 Society for Neuroscience $0270-6474 / 94 / 140167-20 \$ 05.00 / 0$
}

Central cholinergic mechanisms have been implicated in cortical activation (Détári and Vanderwolf, 1987; Sillito and Murphy, 1987; Buzsáki and Gage, 1991; Richardson and DeLong, 1991), arousal (Singer, 1979; Semba, 1991), and memory (Drachman, 1981; Bartus, 1982; Bartus et al., 1982; Sahakian, 1988; Kesner and Johnson, 1991; Olton et al., 1991 a). The basal forebrain cholinergic system (BFCS) provides the major cholinergic innervation to cortical and limbic structures (Mesulam et al., 1983; Rye et al., 1984; Struble et al., 1986; Kitt et al., 1987; Mesulam and Geula, 1988; Herrera-Marschitz et al., 1990).

Degeneration of neurons in the BFCS is thought to be, in part, responsible for the severe cognitive abnormalities associated with Alzheimer's disease (AD) (Bartus et al., 1982; Coyle et al., 1983). Shrinkage and/or loss of neurons in this region occurs in AD patients (Perry et al., 1982; Whitehouse et al., 1982; Arendt et al., 1983; Nagai et al., 1983; Mann et al., 1984; Saper et al., 1985; Rinne et al., 1987; Vogels et al., 1990; Iraizoz et al., 1991), and cholinergic markers in the cortical target fields of the BFCS neurons are altered in these individuals (Rossor et al., 1982; Bird et al., 1983; Mash et al., 1985; Koshimura et al., 1986; Perry et al., 1986; Quirion et al., 1986; Flynn et al., 1991; Pascual et al., 1991). Some of these cholinergic abnormalities are among the earliest and most consistent findings that occur in patients with $\mathrm{AD}$.

In animals, pharmacological studies indicate that central cholinergic mechanisms may be important for cognitive processes (see reviews in Bartus, 1982; Spencer and Lal, 1983; Hagan and Morris, 1988). Lesions of the BFCS in rodents produce many different cognitive impairments (for reviews, see Olton and Wenk, 1987; Kesner, 1988; Olton et al., 1991a,b). Considerably fewer investigations have focused on nonhuman primate models with perturbations of this system. Lesions of the nucleus basalis of Meynert (NBM) in marmosets or squirrel monkeys impaired the ability to learn, remember, or reverse simple visual discriminations (Ridley et al., 1985; Irle and Markowitsch, 1987; Roberts et al., 1990, 1992), and to perform accurately in the visual recognition task of delayed nonmatching-to-sample (DNMS) (Irle and Markowitsch, 1987; Ridley et al., 1988a). Damage to the nucleus of the vertical limb of the diagonal band of Broca (NDBB) in marmosets impaired visuospatial discriminations and spatial reversals (Ridley et al., 1988b, 1989). Although limited lesions of the NBM in cynomolgus monkeys did not impair memory (Aigner et al., 1987), combined damage of the NBM, NDBB, and medial septum (MS) produced transient mild deficits in DNMS (Aigner et al., 1991). Thus, limited information 
is available about the behavioral cffects of BFCS lesions in primates in tasks that determine a broad spectrum of cognitive abilities.

The present study systematically investigated the behavioral effects of large lesions of the BFCS in cynomolgus monkeys. Magnetic resonance imaging (MRI) techniques were used to guide injections of ibotenic acid throughout the BFCS. We recognize that populations of noncholinergic neurons also exist in the BFCS and that ibotenic acid injections destroy noncholinergic and cholinergic neurons. However, because the basal forebrain consists of a number of structures, the term "BFCS" is used to identify the specific regions in the basal forebrain where the injections were placed (i.e., the MS, NDBB, and NBM).

Extensive pre- and postoperative testing in a variety of visual and spatial behavioral tasks, with varying levels of difficulty, assessed a number of cognitive functions, including acquisition, recent memory, long-term memory, and attention. These tasks were chosen because they are sensitive to detecting memory deficits following lesions in selective cortical and limbic targets of BFCS neurons (Cowey and Gross, 1970; Goldman and Rosvold, 1970; Mahut, 1971; Mishkin, 1982; Horel et al., 1984; Voytko, 1985, 1986; Zola-Morgan and Squire, 1986; Phillips et al., 1988; George et al., 1989; Martin-Elkins et al., 1989; ZolaMorgan et al., 1989a,b; Gaffan and Murray, 1992), and many of these tasks are sensitive to pharmacological manipulation of the cholinergic system (Bartus and Johnson, 1976; Bartus, 1978; Penetar and McDonough, 1983; Ridley et al., 1984; Aigner and Mishkin, 1986; Rupniak et al., 1989). Moreover, some of these tasks have been used to assess cognitive abilities in patients with AD (Freedman and Oscar-Berman, 1986; Irle et al., 1987; Sahakian et al., 1988; Parasuraman et al., 1992). To determine if lesions of the BFCS increased sensitivity to anticholinergic drugs, responses to injections of scopolamine were evaluated in DNMS and simultaneous nonmatching-to-sample (SNMS) tasks.

\section{Materials and Methods}

\section{Subjects}

Eight experimentally naive cynomolgus (Macaca fascicularis) monkeys, weighing $2.5-3.4 \mathrm{~kg}$ at the start of testing, were the subjects of this study. Five monkeys received injections of ibotenic acid in the BFCS (LES: LES-46, LES-456, LES-617, LES-029, LES-003), and three monkeys were sham-operated controls (CON). An ad libitum diet of monkey chow was supplemented with fruit. Fluids were obtained during daily sessions in the test apparatus, and the amount of fluid received was adjusted to ensure the health and motivation of each monkey.

\section{Apparatus}

The behavioral apparatus was similar to that previously described (Horel et al., 1987) with the following exceptions: the primate chair was placed inside a sound-attenuated test box equipped with a fan, houselight, and a closed-circuit television camera, and an amber stimulus light was positioned above each of the two side response screens and was used in the attention task.

\section{$M R I /$ surgery}

MRI was used to obtain coordinates for placement of ibotenic acid injections and to check the accuracy of previous injections. Three MRI sessions were conducted in each LES monkey and one session in each CON monkey. For each LES monkey, one MRI session was performed on each of $2 \mathrm{~d}$ of surgery. The third MRI session followed the last surgery and was used to check the accuracy of the final series of injections. Stereotaxic coordinates for each of two surgeries in CON monkeys were obtained in one MRI session.

To prepare for MRI and the immediately following surgery, each monkey was sedated with ketamine (Ketaset, $14 \mathrm{mg} / \mathrm{kg}, \mathrm{i} . \mathrm{m}$.) and $\mathrm{xy}-$ lazine (Rompun, $1.2 \mathrm{mg} / \mathrm{kg}, \mathrm{i} . \mathrm{m}$.) and given atropine sulfate $(0.1-0.2$ $\mathrm{mg}$, i.m.), and in some cases, dexamethasone sodium phosphate (Decadron, $1 \mathrm{mg}$, i.m.). Supplemental doses of ketamine and xylazine were administered as needed to ensure adequate sedation throughout the 1.5 hr MRI procedure. Following intubation, the head of the monkey was placed in a specially constructed, non-ferromagnetic stereotaxic frame that was similar to a previously described model (Saunders et al., 1990). The stereotaxic frame and monkey were placed in a 1.5 tesla General Electric Signa MRI unit (Milwaukee, WI) and aligned using a landmark laser alignment system. Capillary tubes containing vegetable oil were placed within bored holes inside the earbars of the stereotaxic frame. Images of these tubes were later used as reference points to determine antcrior-posterior measurements.

Each MRI session contained four scans. Following an initial series of transverse scout MRI scans [echo time (TE) $=20 \mathrm{msec}$, repetition time $(\mathrm{TR})=400 \mathrm{msec}$, field of view $(\mathrm{FOV})=16 \mathrm{~cm}$, display matrix $=256$ $\times 128$, number of excitations (NEX) $=1,5$-mm-thick images with a 5 $\mathrm{mm}$ gap between images] and a sagittal single echo series $(\mathrm{TE}=90$ msec, TR $=3000 \mathrm{msec}$, FOV $=10 \mathrm{~cm}$, display matrix $=256 \times 128$, $\mathrm{NEX}=1,3 \mathrm{~mm}$ images with no gap between images), two interleaved transverse double echo series $(\mathrm{TE} 1=30 \mathrm{msec}$, TE2 $=90 \mathrm{msec}, \mathrm{TR}=$ $3000 \mathrm{msec}, \mathrm{FOV}=10 \mathrm{~cm}$, display matrix $=256 \times 256, \mathrm{NEX}=1$ ) were obtained for all monkeys. These double echo series provided 3-mmthick sections with no gap between images, and the two series were offset from each other by $1.5 \mathrm{~mm}$. This procedure produced high-resolution coronal images throughout the entire extent of the MS, NDBB, and NBM. Coordinates for intended targets within the BFCS were determined from these double echo images using MRI analysis software.

An additional series of MRI scans was obtained in LES monkeys in the third MRI session. This series consisted of transverse volume scans $(\mathrm{TE}=20 \mathrm{msec}, \mathrm{TR}=100 \mathrm{msec}, \mathrm{FOV}=10 \mathrm{~cm}$, display matrix $=256$ $\times 128, \mathrm{NEX}=2$ ) that provided $0.7-\mathrm{mm}$-thick images at 28 locations. Needle tracks were prominent on these images and provided an additional means of checking the accuracy of injections.

Stereotaxic surgery was performed in two stages. The left hemisphere was operated first, followed 1-2 weeks later by the right hemisphere. Initially, deep anesthesia was induced and maintained with sodium pentoharbital $(10 \mathrm{mg} / \mathrm{kg}$, i.v.) for all monkeys. However, the combination of this barbiturate and the ibotenate injections in LES-46 and LES-456 produced an extended postoperative recovery. To decrease postoperative recovery time, inhalation anesthesia using isoflurane (Forane) and nitrous oxide was used for LES-617, LES-003, and LES-029. Temperature and respiration were measured continuously throughout surgery, while an electrocardiogram monitored heart rate. Intravenous fluids were infused throughout surgery. Antibiotics of $\mathrm{G}$ penicillin (Bicillin, $1 \mathrm{cc}, \mathrm{i} . \mathrm{m}$.) or chloromycetin sodium succinate (chloroamphenicol, $25 \mathrm{mg} / \mathrm{kg}$, i.m.) were administered at the beginning and conclusion of surgery.

The head was draped for sterile surgery, and an incision was made down the midline. The skin, connective tissue, and temporalis muscle were retracted. In the first surgery, after measuring the dorsal-ventral coordinate of the top of the skull for each injection site, a $2 \mathrm{~cm} \times 3 \mathrm{~cm}$ bone flap was drilled over the midline of the skull. A dural flap was made over the left hemisphere, and exposed dura and cortex were covered with a gelatin sponge (Gelfoam) and regularly moistened with sterile saline. In the second surgery, the edge of the intact skull on the right side was used for the dorsal-ventral coordinate, and the dural flap was made over the right hemisphere.

Bilateral injections $(10 \mu \mathrm{g} / \mu \mathrm{l})$ of ibotenic acid (Sigma, St. Louis, MO) were made in the MS, NDBB, and NBM in LES monkeys. The ibotenic acid was dissolved in phosphate-buffered saline, brought to a $\mathrm{pH}$ of 7.7 , aliquoted into Eppendorf tubes, and frozen at $-70^{\circ} \mathrm{C}$. A new aliquot was thawed for each surgery. A $10 \mu 1$ syringe fitted with a 30 gauge needle (Hamilton Co., Reno, NV) was used to make the injections. A total of 13 or 14 injections were made bilaterally in the basal forebrain of LES-46 and LES-456: 1 injection in MS, 1 in NDBB, 11 or 12 in NBM. Because the size of the lesion produced by these injections was small (see Results), LES-617, LES-003, and LES-029 received 17-19 injections in each hemisphere: 2 injections in MS, 1 in NDBB; 14-16 in NBM. To make injections in LES monkeys, the tip of the needle was lowered to the desired site and $1 \mu \mathrm{l}$ of the ibotenate solution was injected during 5-10 min. The needle was left in place for an additional $5 \mathrm{~min}$, withdrawn, and moved to the next site. For the MS and NDBB, a $10^{\circ}$ angle from midline was used for the injections because of complications encountered by making direct vertical injections into these midline structures. In CON monkeys, the needle tip was lowered to a depth of 


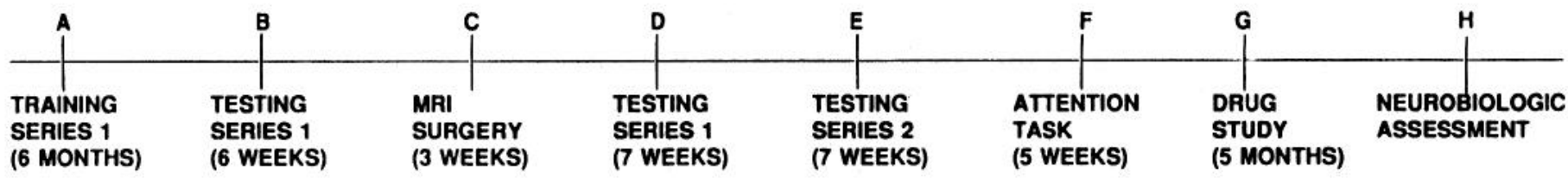

Figure 1. Time course of experimental design. Preoperative training $(A)$ and preoperative testing $(B)$ occurred on a series of behavioral tasks (series 1). $C$, Ibotenic acid injections were made in the BFCS with the use of MRI. $D$, Postoperatively, series 1 was tested again as soon after surgery as possible. $E$, A second series of behavioral tasks (series 2) was given. $F$, An attention task was given. $G$, Drug testing with scopolamine occurred. $H$, At the conclusion of the study, neurochemical and histologic assessments were made of the neurotoxic lesions.

$1 \mathrm{~mm}$ above the desired site, left in place for $5 \mathrm{~min}$, and withdrawn without expelling any material. Following the final injection, dura, connective tissue, and scalp were sutured in layers, and the bone flap sutured back in place. The monkey was placed on heating pads in an observation cage and continuously monitored. Antibiotics were administered on alternate days for $5 \mathrm{~d}$. Decadron was administered on a decreasing dosage schedule for 5-7 d in LES-003 and LES-029.

\section{Tissue preparation and analysis}

At the completion of all behavioral testing, each monkey was sedated with ketamine $(14 \mathrm{mg} / \mathrm{kg}$, i.m.), deeply anesthetized with sodium pentobarbital $(35 \mathrm{mg} / \mathrm{kg}$, i.v.), and perfused through the left ventricle with cold, $0.1 \mathrm{~m}$ phosphate-buffered saline ( $\mathrm{pH} \mathrm{7.4)}$ ). To obtain fresh cortical samples of tissue for neurochemical assays and optimally prepare the basal forebrain for subsequent morphological analyses, a slow continuous flow of buffer was maintained while the skull cap was removed, and tissue from 12 cortical target fields of the BFCS neurons was bilaterally dissected. These samples were frozen $\left(-70^{\circ} \mathrm{C}\right)$ and processed for choline acetyltransferase (ChAT) neurochemistry (see below). Following replacement of the skull cap, $4 \%$ paraformaldehyde $(\mathrm{pH} 7.4)$ was perfused, followed by a solution of $4 \%$ paraformaldehyde and $10 \%$ sucrose. Each brain was blocked coronally and postfixed in $4 \%$ paraformaldehyde and $10 \%$ sucrose for an additional $4 \mathrm{hr}$. Blocks were cryoprotected in $30 \%$ sucrose in $0.1 \mathrm{~m}$ phosphate buffer until they sank, at which time they were frozen and stored at $-70^{\circ} \mathrm{C}$. Sections through the entire MS, NDBB, and NBM were cut at $40 \mu \mathrm{m}$ on a freezing-sliding microtome. Series of sections were stained with cresyl violet, histochemically processed for acetylcholinesterase (AChE) and immunocytochemically processed for nerve growth factor receptor (NGFR) or ChAT. Sections processed for immunocytochemistry were used to identify remaining cholinergic neurons in the BFCS to determine the extent of the lesion.

Histology. Two histochemical methods were used to demonstrate
AChE staining. The first procedure was a modified protocol (Hedreen et al., 1983) of the Karnovsky-Roots method (Karnovsky and Roots, $1964)$ that provides exceptional visualization of fiber processes containing AChE. The second procedure was that of Tsuji (1974) that provides optimum visualization of cell bodies containing AChE. Immunocytochemical demonstration of NGFR or ChAT followed standard procedures published elsewhere (Voytko et al., 1992). Monoclonal antibodies used were directed against ChAT (1:250) (AB8, courtesy of Dr. Bruce Wainer, Department of Pathology, University of Chicago) or NGFR (1:1000) (human anti-NGF receptor; Boehringer Mannheim, Indianapolis, IN).

The extent of the lesion was determined by microscopic examination for cell loss, gliosis, and reduced AChE staining. This histology was plotted on a series of line drawings for each monkey and transferred to a series of five representative levels through the basal forebrain.

Measurement of ChAT activity. Cortical tissue samples were assayed for ChAT activity according to the method of Fonnum (1969). To preserve the integrity of the BFCS for histology, ChAT assays were limited to cortical regions and not performed in the amygdala and hippocampus. Levels of ChAT activity were measured in tissue samples collected bilaterally from regions in frontal (frontal pole, superior, dorsolateral, inferior, precentral), temporal (temporal pole, superior, middle and inferior gyri), parietal (inferior and postcentral), and occipital (striate) cortices. Because tissues from one CON monkey could not be included in this analysis, because of the inability to harvest the samples under optimal conditions, ChAT measurements performed in three monkeys that were not assessed behaviorally were included in the CON data.

\section{Behavioral procedures}

The experimental design had eight stages as illustrated in Figure 1. Preoperative training took place on a series of behavioral tasks (series 1) and preoperative testing of series 1 occurred as close to the time of
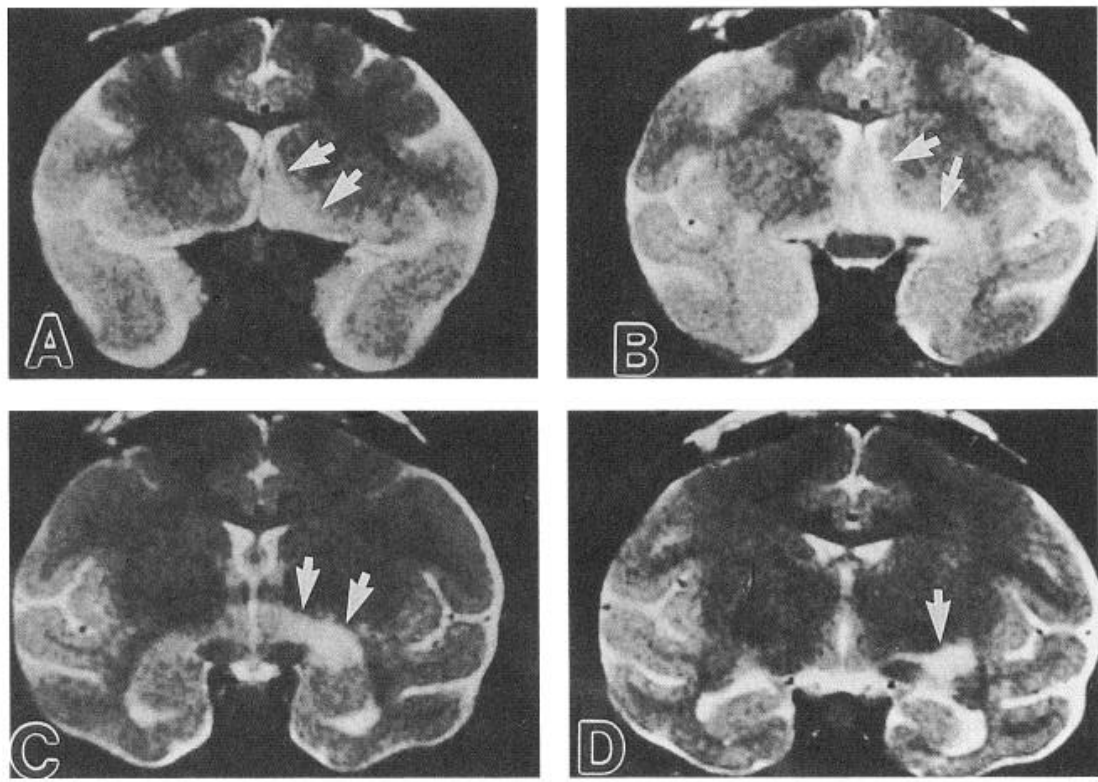

Figure 2. Examples of images obtained in MRI: transverse double echo images taken in LES-617 1 week after ibotenic acid injections were made in the right hemisphere. Arrows indicate an increase in signal that corresponds to the site of injections made in the right hemisphere. The left hemisphere was injected 2 weeks prior to these scans and an increase in signal, which had been obvious in that hemisphere 1 week after surgery, is no longer visible. $A$, level of MS and NDBB; $B$, level of anterior NBM; $C$, level of intermediate NBM; $D$, level of posterior NBM. 


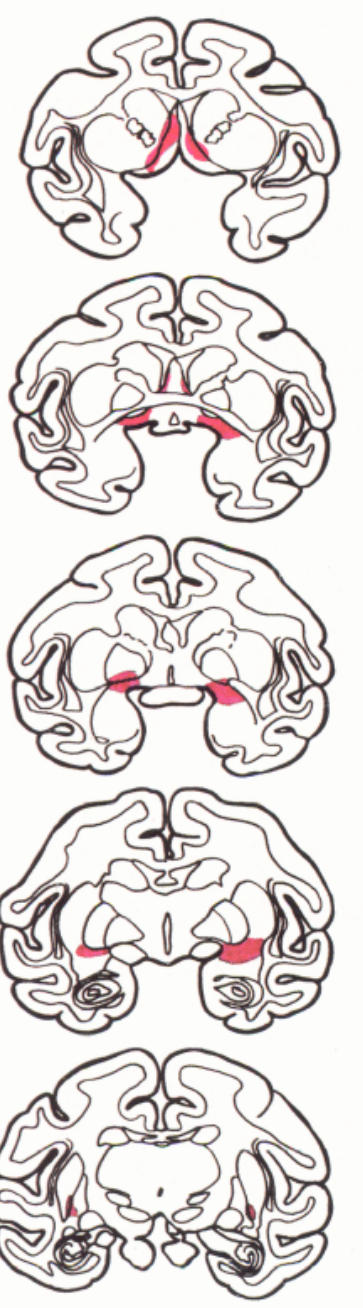

029
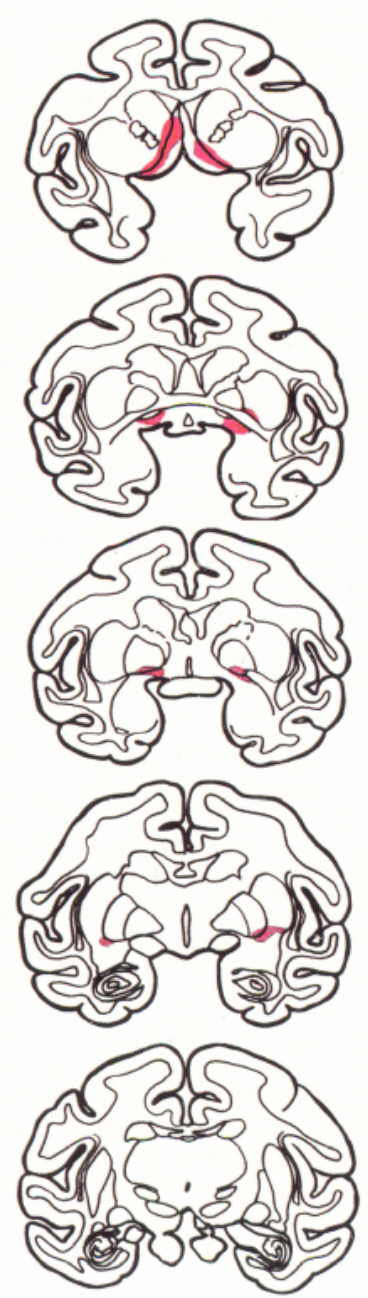

456
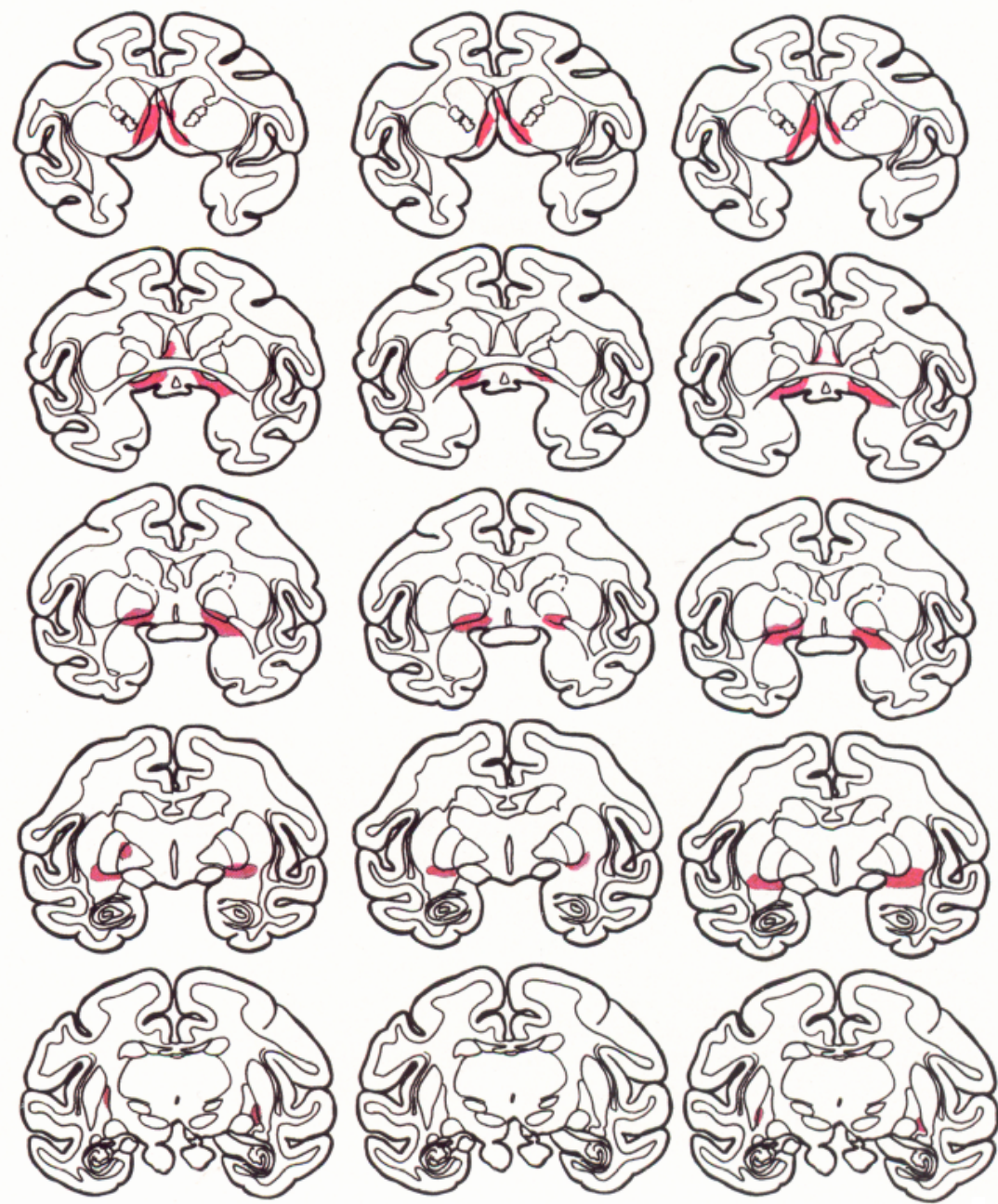

617

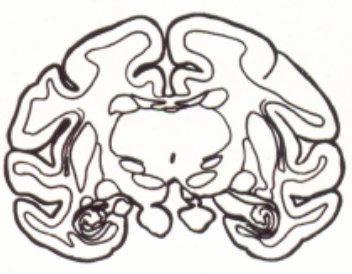

46

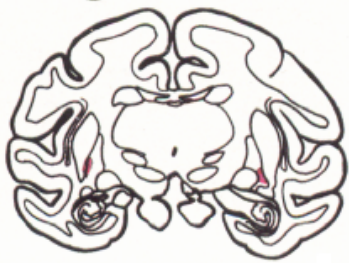

003

Figure 3. Illustration of the extent of the lesion at five standard levels through the BFCS in each LES monkey. Red shaded regions indicate extent of the lesion. Extent of the lesion was determined by cell loss, gliosis, and reduced AChE staining on serial sections throughout the basal forebrain.

surgery as possible to assess ability on all tasks immediately before surgery. Postoperative testing included repetition of the preoperative tasks, a new series of memory tasks (series 2), an attention task, and evaluation of the behavioral effects of the cholinergic antagonist scopolamine hydrobromide on performance in a simultaneous and delayed nonmatching-to-sample task. Because of the size of the study, the behavioral procedures, results, and a brief discussion at each stage of the study are presented separately, followed by a general discussion. Statistical analyses were performed for all behavioral tasks using repeated measures and mixed model analyses of variance (ANOVA) with groups being the between factor.

\section{Results}

Histology

Examples of brain images obtained in the MRI following a series of injections made in the right hemisphere of LES-617 are shown in Figure 2. The site and extent of the BFCS lesion on histological slides highly correlated with the location of the lesion on MRI scans. By using MRI scans to determine stereotaxic coordinates for injections of ibotenic acid into the BFCS, injections were accurately placed throughout all subdivisions of the BFCS, including the most posterior aspect of the NBM (Ch4p; Mesulam et al., 1983). The extent of gliosis and cell loss associated with the neurotoxic lesions is illustrated on five standard sections through the MS, NDBB, and NBM for each LES monkey (Fig. 3). Photographic examples of the loss of NGFR-positive cells in this region are shown in Figure 4.

The most consistent and greatest damage within the BFCS was in the NBM. The NBM lesion was particularly large in LES029, LES-617, and LES-003, in which a greater number of ibotenic acid injections were made. In these three monkeys, cell loss ranged from extensive to nearly complete in all subdivisions of the NBM, including the posterior aspects. LES-456 and LES46 had smaller lesions in the NBM, especially in posterior aspects, reflecting the fewer injections made in these initial monkeys. Damage within the MS and NDBB was generally less extensive than that in the NBM, with the largest lesion in these regions occurring in LES-617. AChE-fiber staining in the basal nucleus of the amygdala was greatly reduced in all LES monkeys, whereas AChE-fiber staining in hippocampus was not significantly altered (Fig. 5). Damage outside the BFCS was minimal and restricted to structures surrounding the BFCS, that is, in anteroventral cingulate cortex, lateral septal nucleus, olfactory tubercle, nucleus accumbens, ventral striatum, ventral globus 

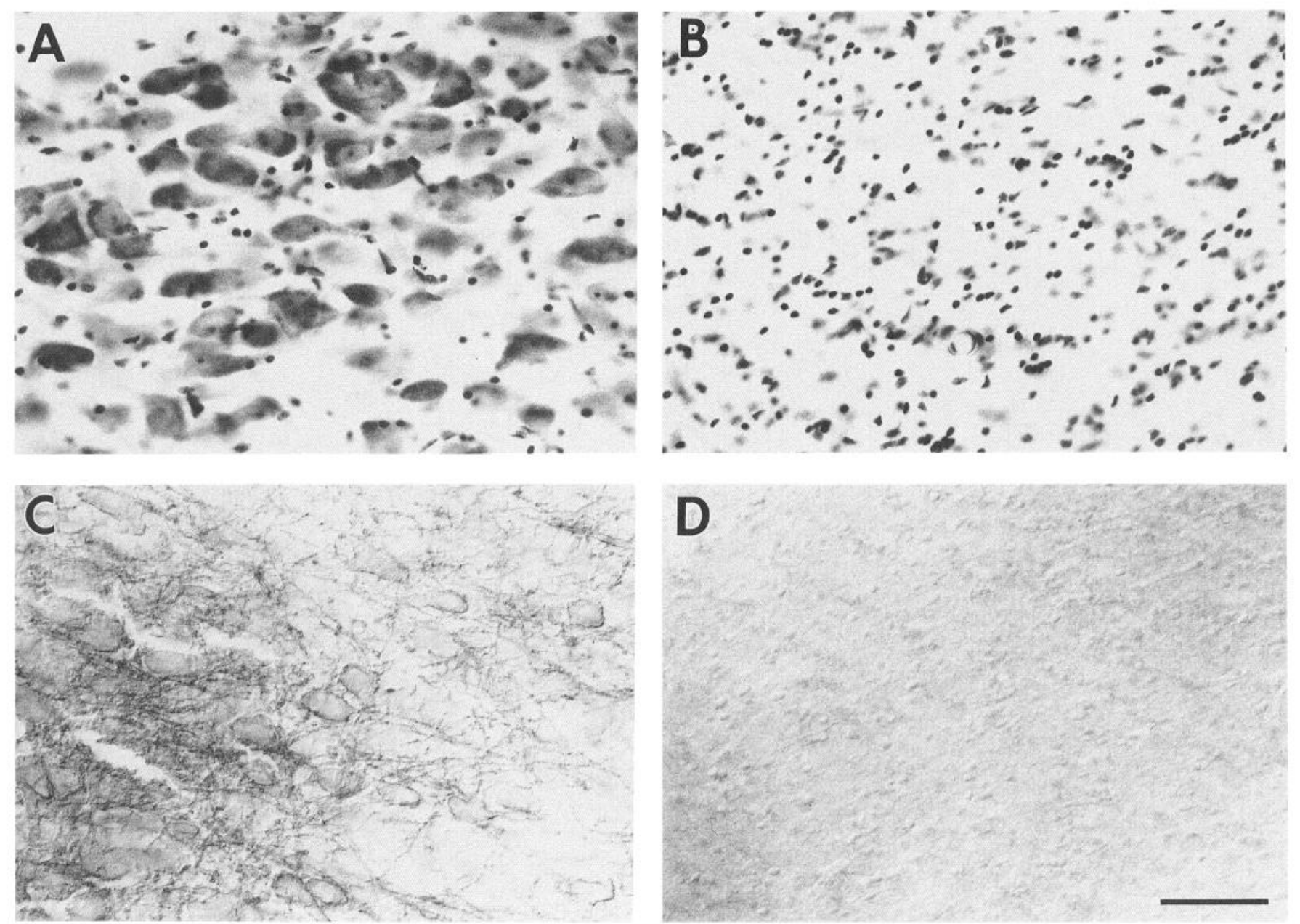

Figure 4. Photomicrographs with differential interference contrast of cell loss in the anterior aspect of the NBM following injections of ibotenic acid. $A$ and $C$, control monkey; $B$ and $D$, LES-029. $A$ and $B$, sections stained with cresyl violet; $C$ and $D$, sections processed for NGFR. Note the absence of hyperchromic magnocellular neurons and NGFR-positive neurons in the NBM following the neurotoxic injections. Scale bar, $50 \mu \mathrm{m}$.

pallidus, and dorsal aspects of the medial, anterior, and central amygdala nuclei.

\section{Measurement of ChAT activity}

ChAT levels were similar in both hemispheres for each monkey for the regions sampled [three-way ANOVA, $F(1,5)=1.10, p$ $>0.05]$, and the data have been collapsed across this measure for each group. Additional ANOVAs on these data revealed that mean levels of ChAT activity (nM/mg protein $/ \mathrm{hr}$ ) were reduced greatly in LES monkeys with effects of group [two-way ANOVA, $F(1,8)=12.19, p=0.008]$, area $[F(8,64)=21.74, p<0.001]$, and the interaction of group $\times$ area $[F(8,64)=5.69, p<0.001]$ (Table 1). Pairwise comparisons between groups indicated that decreases in ChAT levels were significant in LES monkeys for all regions (one-way ANOVAs, $p<0.03$ ), except for frontal pole, superior temporal gyrus, and occipital lobe $(p>0.05)$ (Fig. 6). These decreases in ChAT activity were especially notable in LES-029, LES-617, and LES-003 that had received the largest number of injections. In these monkeys, ChAT activity was reduced to levels ranging from $48 \%$ to $74 \%$ of CON values. In LES-456 and LES-46, in which fewer injections had been made, reductions in ChAT levels were lower, ranging from $12 \%$ to $62 \%$.

\section{Postoperative recovery}

LES-46 and LES-456, which received 13 or 14 injections of ibotenic acid in each hemisphere, had temporary contralateral neglect (i.e., disuse of the contralateral limbs and nonresponsiveness to touch), and they circled toward the side of the lesion. These symptoms disappeared in 1-2 d following each surgery. Aside from these signs, these monkeys had otherwise normal behavior during postoperative recovery.

Compared to the initial two LES monkeys, LES-029, LES617, and LES-003, in which 17-19 injections were made in each hemisphere, had minor postoperative difficulties after the first surgery and more severe postoperative complications following the second surgery. Following the first surgery, anorexia and adipsia were present for the first postoperative day, with contralateral parasthesis, flaccidity or passive extension of the hindlimb and forelimb, head tilt, and slow circling motions toward the lesioned hemisphere present for 1-3 d postoperatively.

Following the second surgery, these same symptoms appeared in a more exaggerated and prolonged fashion, and therefore constant surveillance was maintained throughout postoperative recovery. Because anorexia and adipsia were present for 7-14 d, subcutaneous fluids of 1:1 lactated Ringer's and 5\% dextrose 

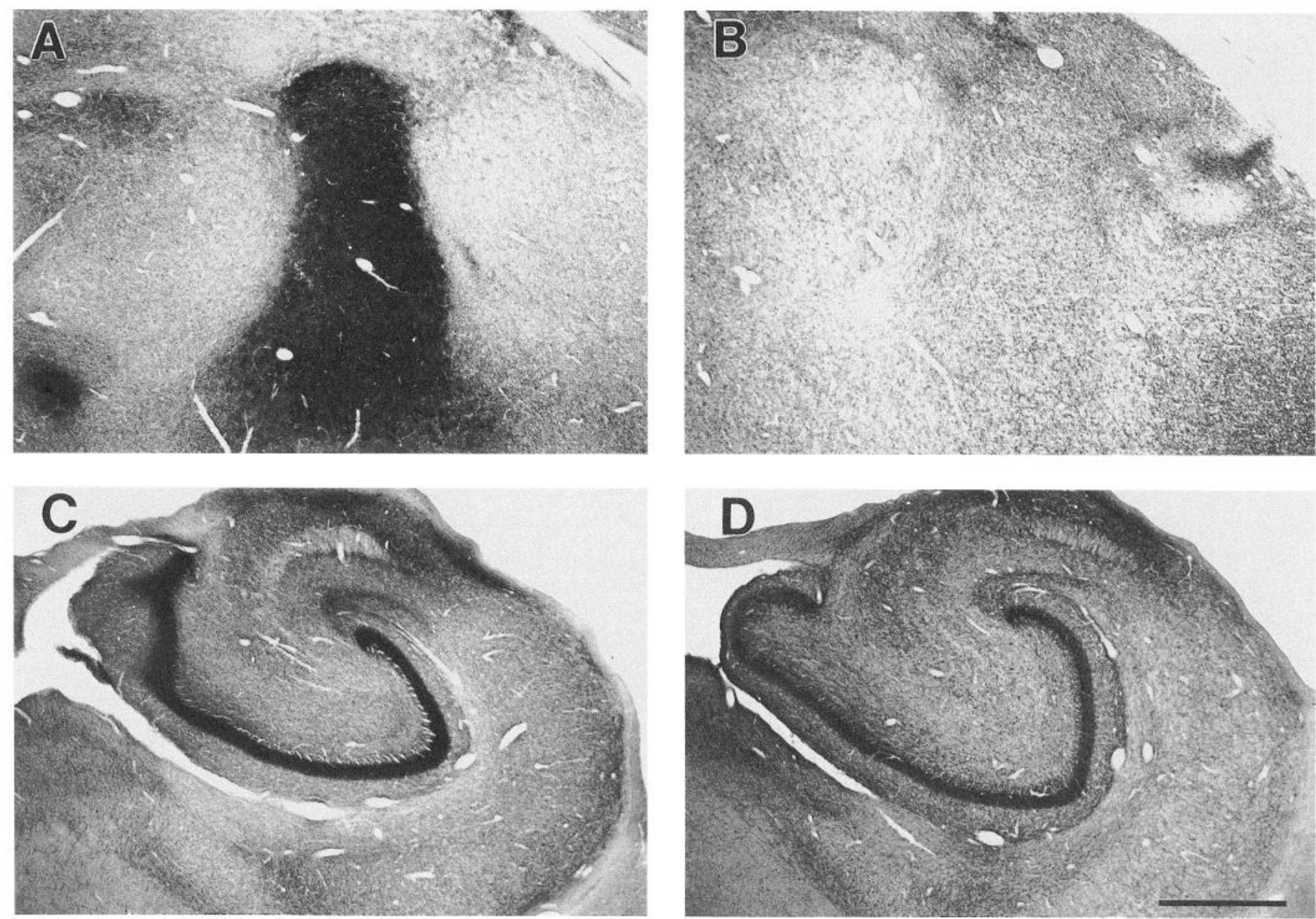

Figure 5. Photomicrographs illustrating AChE-fiber staining (Hedreen et al., 1983) in amygdala and hippocampus. $A$ and $C$, control monkey; $B$ and $D$, LES-617. $A$ and $B$, amygdala; $C$ and $D$, hippocampus. Note the significant decrease in AChE-fiber staining in the basal nucleus of the amygdala in the lesioned monkey, whereas AChE-fiber staining was not greatly altered in the hippocampus. Scale bar, $1 \mathrm{~mm}$.

in normal saline and/or nasogastric tube feedings of infant formula were administered three times a day until normal eating and drinking occurred. These procedures kept weight loss at a minimum, and in some cases weight gain was seen. Ipsilateral

Table 1. Mean ( \pm SEM) levels of ChAT activity (nM/mg protein/hr)

\begin{tabular}{lrr} 
Regions sampled & \multicolumn{1}{c}{ Controls } & \multicolumn{1}{c}{ Lesioned } \\
\hline 1. Frontal pole & $10.1 \pm 1.4$ & $6.0 \pm 1.4$ \\
2. Superior frontal & $13.2 \pm 1.6$ & $6.2 \pm 1.2$ \\
3. Dorsolateral frontal & $8.3 \pm 0.6$ & $5.4 \pm 0.8$ \\
4. Inferior frontal & $8.7 \pm 0.8$ & $4.9 \pm 0.7$ \\
5. Precentral gyrus & $15.5 \pm 1.0$ & $6.8 \pm 1.1$ \\
6. Postcentral gyrus & $10.7 \pm 0.9$ & $7.3 \pm 0.8$ \\
7. Inferior parietal & $7.4 \pm 0.4$ & $3.6 \pm 0.7$ \\
8. Superior temporal & $14.5 \pm 2.2$ & $8.3 \pm 1.6$ \\
9. Middle temporal & $15.9 \pm 1.3$ & $5.4 \pm 0.9$ \\
10. Inferior temporal & $12.7 \pm 2.2$ & $5.9 \pm 0.9$ \\
11. Temporal pole & $9.8 \pm 2.3$ & $8.8 \pm 2.4$ \\
12. Occipital lobe & $7.9 \pm 1.2$ & $10.8 \pm 2.9$ \\
\hline
\end{tabular}

Levels of ChAT were similar in both hemispheres in each monkey for the regions sampled, and the data have been collapsed across this measure for each group.

The number before each region refers to the area in the diagram in Figure 6. circling as well as contralateral parasthesis and limb extensions disappeared after 2-3 d postoperatively. In some instances, the monkeys were relatively unreactive to being touched or approached, especially contralateral to the lesioned hemisphere, and were akinetic for periods of time. In other instances, they appeared to be almost normal in activity and reactivity. While supporting themselves in a sitting position, they displayed periods in which they seemed to drift in and out of awareness as judged by a blank stare, lack of movement, and nonresponsiveness to the environment. No signs of pain or discomfort were evident during the postoperative recovery.

Thermoregulation was generally poor for $2 \mathrm{~d}$ immediately following the second surgery. During this period, body temperature was monitored and maintained with the use of heating pads or a heat lamp. After 7-14 d, normal behaviors of eating, drinking, activity, and reactivity returned. Monkeys were returned to their home cage only after sufficiently demonstrating fully recovered behaviors for 3-4 d.

\section{Behavioral series 1}

Following preoperative training (Fig. 1, stage A), the following series of tasks were assessed immediately prior to surgery (Fig. 1 , stage B), and again assessed after recovery from surgery (Fig. 1 , stage D). The order of training and testing is listed in Table 2. 


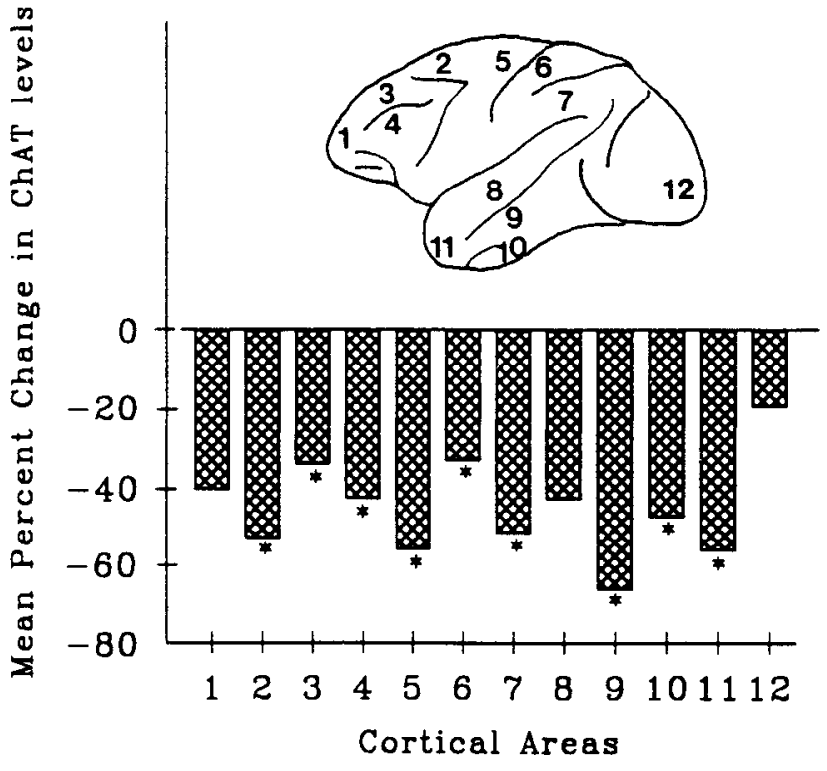

Figure 6. Percentage change in ChAT levels (nM/mg protcin $/ \mathrm{hr}$ ) in 12 cortical areas sampled in LES monkeys. Line through zero represents control levels normalized to zero. Because ChAT levels were similar in both hemispheres for regions sampled, the left and right ChAT values have been added for each region. Each bar represents the change in ChAT levels in LES monkeys compared to CON monkeys for each cortical region. The diagram indicates the cortical regions bilaterally sampled and plotted in the graph. *, a significant decrease compared to CON monkeys $(p<0.02)$. 1 , frontal pole; 2 , superior frontal; 3 , dorsolateral frontal; 4 , inferior frontal; 5 , precentral gyrus; 6 , postcentral gyrus; 7 , inferior parietal; 8 , superior temporal gyrus; 9 , middle temporal gyrus; 10 , inferior temporal gyrus; 11 , temporal pole; 12 , occipital lobe.

\section{Procedures}

DNMS with delays. A trial began with the appearance of a projected image of an object (sample) on the center screen (cue phase). After 10 responses to the center screen, a reward was delivered, the sample was removed, and a delay was initiated. At the end of the delay, one object was projected on each of the two side screens (choice phase). One object (match) was identical to that which had been presented as the sample. The other object (nonmatch) was a novel stimulus. The appearance of the match and nonmatch stimuli on the two side screens was determined pseudorandomly. The correct strategy was to respond to the screen containing the nonmatch stimulus. Two responses to the nonmatch stimulus produced a reward for each response and initiated an intertrial interval (ITI) of $15 \mathrm{sec}$. Any response to the match stimulus resulted in no reward, immediate removal of all stimuli from the screens, and a $35 \mathrm{sec}$ ITI. Color slides of over 1000 common objects comprised the pool of stimuli.

Training on DNMS (stage A) began with a 0 sec delay. Blocks of 20 trials were given for a maximum of 160 trials per daily session. The delay was advanced automatically in $1 \mathrm{sec}$ increments each time 17 correct trials occurred in 20 sequential trials until a delay of $60 \mathrm{sec}$ was reached. A variable delay version of DNMS was then introduced with delays of $0,10,30$, and 60 sec randomly presented within a daily test session, with the constraint that no delay was repeated until all had been presented once. Each delay was examined for 40 trials per session, with a daily session containing a total of 160 trials. Use of the variable delay version of DNMS allowed assessment of the rate of forgetting and controlled for possible confounding effects of

\section{Table 2. Behavioral series 1 order of testing}

Delayed nonmatch-10-sample $(0,10,30,60 \mathrm{sec}$ delays $)$

Delayed nonmatch-to-sample (list length of 3 )

Delayed response $(0,5,10$ sec delays $)$

Simple object discriminations

Concurrent object discriminations (20 pairs)

practice, satiation, fatigue, and so on, between daily sessions. Training continued until a mean choice accuracy of at least $90 \%$ correct was achieved across all delays for two sessions. The variable delay DNMS task was tested for $3 \mathrm{~d}$ preoperatively (stage B) and postoperatively (stage D) in the same manner as during training. The dependent measure was choice accuracy in 100 trials per dclay over the $3 \mathrm{~d}$.

DNMS with a list length of 3 . The procedure was similar to that described for DNMS with delays except that three sample objects were shown in succession at $5 \mathrm{sec}$ intervals on the center screen during the cue phase of each trial. Five responses to each sample produced a reward. A 5 sec delay occurred between the appearance of the last sample and the choice phase. In the choice phase, each of the three sample objects was paired with a novel object and shown in succession on the side screens, at $5 \mathrm{sec}$ intervals, in the same order as in the cue phase. The correct strategy was to respond to the novel object of each pair. A set consisted of the presentation of three samples in a cue phase and the corresponding three pairs of objects in the choice phase. A $20 \mathrm{sec}$ ITI separated sets and a maximum of 240 trials were given in a daily session. Training on this task (stage A) continued until a mean choice accuracy of at least $80 \%$ correct was attained for five sessions. Choice accuracy during one preopcrative (stagc B) and one postoperative (stage D) session of 180 trials was the dependent measure.

Delayed response. A trial began with illumination of one of the two side screens (cue phase). Following a response to the lit screen, a reward was delivered and the light was extinguished. A delay began, and, at the end of the delay, the center screen was illuminated. A response to this screen was required for the trial to proceed, but no reward was given for doing so. This procedure disrupted any positional cuing that the animal may have used to remember the cued side screen. After the delay period, both side screens were lit with white light (choice phase), and the correct strategy to receive a reward was to respond to the side screen that had been illuminated in the cue phase. Two responses to the correct screen produced a reward for each response and no reward was delivered for responses to the incorrect screen. A $15 \mathrm{sec}$ ITI followed a correct response and a 35 sec ITI followed an incorrect response.

During training and testing of delayed response (DR), an adjustable barrier was placed over the front of the primate chair to limit responses to only the preferred arm, which, in all instances, was the right arm. Limiting responses to only one arm also reduced positional cuing during the delay. Monkeys adapted easily to the barrier, which was adjusted to accommodate each monkey comfortably and to allow easy access of the right arm to all three response screens.

Training on DR (stage A) began with a 0 sec delay, with delays progressively increasing by $1 \mathrm{sec}$ intervals each time 17 correct trials were made in 20 sequential trials until a $10 \mathrm{sec}$ delay was reached. At that time, delays of 0,5 , and $10 \mathrm{sec}$ were randomly 


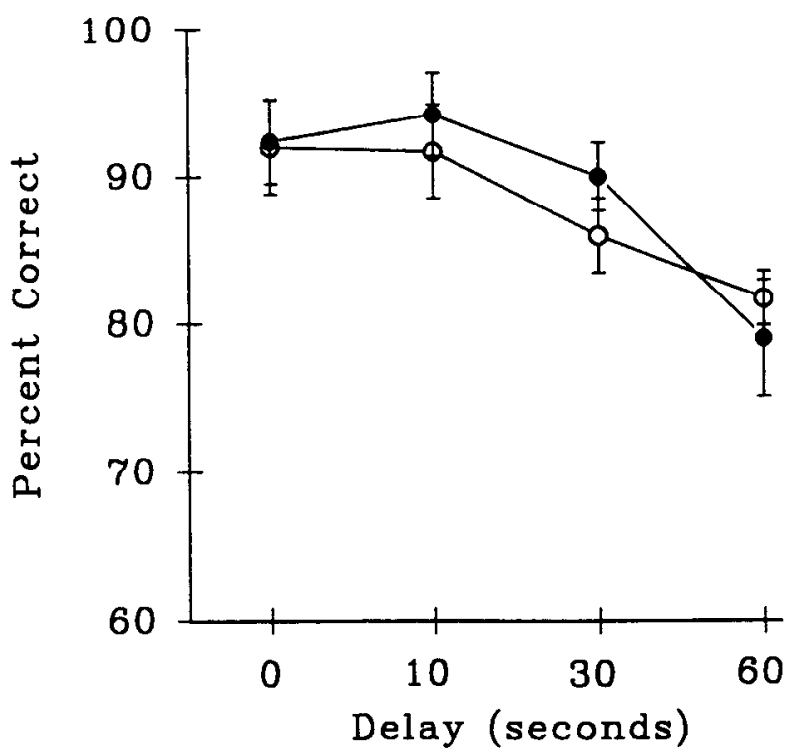

Figure 7. DNMS: postoperative performance in behavioral series 1 . Each delay was tested for 100 trials. Both groups were similar in performance on this task. Choice accuracy decreased as delays increased. O, CON monkeys; $\bullet$ LES monkeys. Bars $=$ SEM

presented within each daily session, in a similar manner to the variable delay DNMS task. Each delay was presented for 50 trials per session, for a total of 150 trials per session. Training continued until choice accuracy reached a mean of at least $90 \%$ correct. Choice accuracy at each delay was the dependent measure examined preoperatively (stage B) and postoperatively (stage D) for two days for a total of 100 trials per delay.

Simple object discriminations: acquisition and retention. Each object of a pair, not used previously, was presented on the two side screens. The side for a particular object varied according to a pseudorandom series. A reward was delivered for each of two responses made to the correct object of the pair. No reward was provided for responses to the incorrect object. A $15 \mathrm{sec}$ ITI followed correct responses and a $35 \mathrm{sec}$ ITI followed incorrect responses. A daily session consisted of a maximum of 200 trials grouped into 20 trial blocks.

(1) Acquisition. Acquisition of three different sets of object discrimination problems was tested in series 1: set 1 (stage A) had five discriminations, set 2 (stage B) had five new discriminations, and set 3 (stage D) had two new discriminations. Acquisition criterion was two consecutive blocks in which mean choice accuracy was greater than or equal to $90 \%$ correct, or for a maximum of 1000 trials. Only one discrimination problem was examined per day, and both trials and errors to criterion were the dependent measures.

(2) Retention. Retention of acquired discrimination problems in sets 1 and 2 was examined for 20 trials per problem, with mean choice accuracy as the dependent measure. Retention of set 1 was examined preoperatively (stage B, 3 months after learning) and again postoperatively (stage D, 7.5 months after learning) in a single test session consisting of a total of 100 trials (20 trials per five problems). Retention of set 2 was examined postoperatively in a test session of 100 trials (stage D, 4 months after learning).

Concurrent object discriminations (20 pairs): acquisition and retention. The procedure was similar to simple object discriminations except that 20 novel pairs of objects were presented in

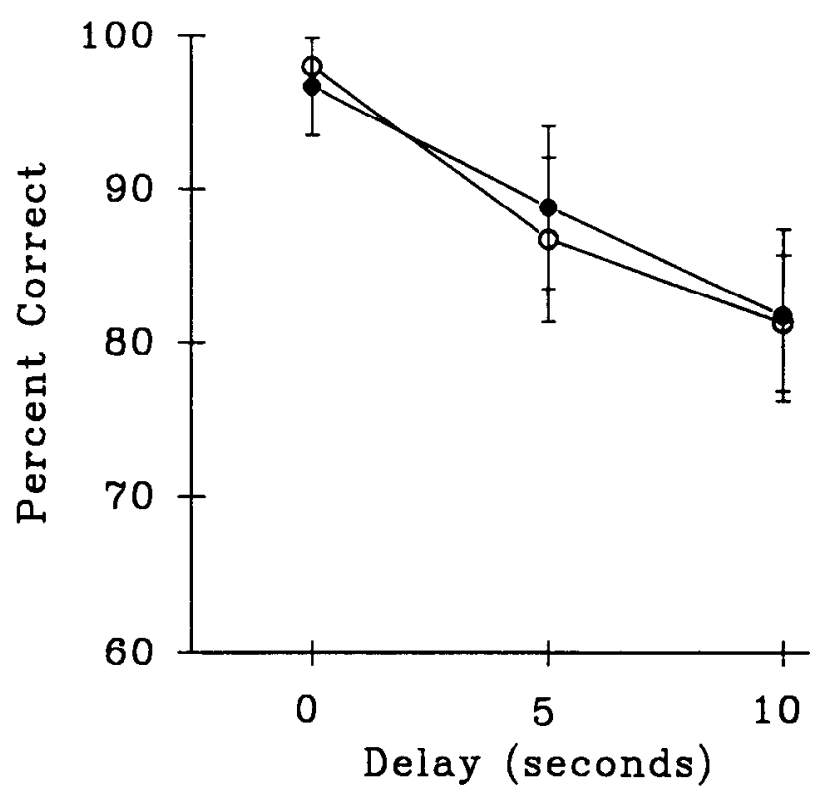

Figure 8. DR: postoperative performance in behavioral series 1. Each delay was tested for 100 trials. Both groups were similar in performance on this task. Choice accuracy decreased as delays increased. Conventions are as in Figure 7.

succession for one trial per day for a total of 20 trials per daily session. The order of presentation of the object pairs was maintained across days, but the left-right position within pairs was changed each day using a pseudorandom series.

(1) Acquisition. Acquisition of three different sets of concurrent object discrimination problems was examined in series 1 : set 1 (stage $A$ ), set 2 (stage $B$ ), and set 3 (stage D). For sets 1 and 2 , testing continued until a mean choice accuracy of at least $90 \%$ correct was achieved over five consecutive sessions. Acquisition of set 3 was limited to a maximum of 15 sessions so that all postoperative testing of series 1 could be performed within as short a time as possible. Sessions to criterion was the dependent measure for acquisition in all sets.

(1) Retention. Sets 1 and 2 were examined for five test sessions. The dependent measure was mean choice accuracy across the five test sessions. Retention of set 1 was examined preoperatively (stage B, 3 months after learning) and postoperatively (stage D, 7 months after learning). Retention of set 2 was examined postoperatively (stage D, 3 months after learning).

\section{Results (hehavioral series l)}

Postoperative examination of series 1 began approximately 3 weeks after the second surgery. LES-617 required a longer postoperative recovery, and testing began 5 weeks after the second surgery in this monkey.

DNMS with delays. Postoperative accuracy on the DNMS task is illustrated in Figure 7. A three-way ANOVA revealed that preoperative and postoperative choice accuracy was similar across and within groups of monkeys $(p>0.05)$. A delay effect $[F(3,18)=19.54, p<0.001]$ indicated that choice accuracy decreased with increasing delays, reflecting increasing demands on memory capabilities for both LES and CON monkeys.

DNMS with a list length of 3 . Both groups were comparable preoperatively and postoperatively. Preoperative accuracy: CON $80.3 \% \pm 2.3 \%$, LES $82.5 \% \pm 4.9 \%$. Postoperative accuracy: CON $75.0 \% \pm 4.0 \%$, LES $81.5 \% \pm 4.5 \%$ (two-way ANOVA, $p$ 
$>0.05)$. Furthermore, within each group of monkeys, preoperative and postoperative levels of accuracy were similar $(p>$ 0.05 ).

$D R$. Postoperative accuracy on the DR task is illustrated in Figure 8. LES and CON monkeys performed this task at similar levels of accuracy preoperatively and postoperatively as determined by a three-way ANOVA $(p>0.05)$. Preoperative and postoperative choice accuracy was similar within each group ( $p$ $>0.05)$. A delay effect $[F(2,12)=20.14, p<0.001]$ reflected greater difficulty with increasing delays.

Simple object discriminations: acquisition and retention. Preoperative and postoperative acquisition was measured in trials and errors to criterion for both CON and LES monkeys. LES monkeys learned simple object discriminations in a comparable manner to CON monkeys, as measured by trials or errors to criterion (two-way ANOVA, $p>0.05$ ), and the ability to learn object discriminations prcopcrativcly or postoperatively was similar for both groups $(p>0.05)$. Set 1: trials, CON $38.4 \pm$ 8.4, LES $25.6 \pm 6.9$; errors, CON $7.7 \pm 2.0$, LES $6.2 \pm 1.3$. Set 2: trials, CON $14.7 \pm 5.8$, LES $14.2 \pm 8.7$; errors, CON 3.1 \pm 1.4 , LES $4.5 \pm 3.1$. Set 3: trials, CON $16.7 \pm 3.3$, LES 30 \pm 8.4 ; errors, CON $8.3 \pm 2.6$, LES $8.3 \pm 1.7$.

Retention of simple object discriminations was also comparable between groups of monkeys (two-way ANOVA, $p>0.05$ ): set 1 (stage B), CON $89.7 \% \pm 2.9 \%$, LES $91.8 \% \pm 1.8 \%$; set 1 (stage D), CON $94.7 \% \pm 3.5 \%$, LES $93.2 \% \pm 1.6 \%$; set 2 (stage D), CON $91.3 \% \pm 4.7 \%$, LES $92.8 \% \pm 1.6 \%$.

Concurrent object discriminations (20 pairs): acquisition and retention. The two groups were comparable in number of sessions to acquire the three sets of concurrent discriminations: set 1, CON 9.0 \pm 2.6 , LES $5.4 \pm 0.7$; set 2, CON $17.3 \pm 7.1$, LES $10.2 \pm 2.2$; set 3 , CON $12.0 \pm 3.0$, LES $13.4 \pm 1.6$ (two-way ANOVA, $p>0.05)$. Focused analyses of an effect of sets $[F(2,12)$ $=6.97, p=0.01]$ indicated that sets 2 and 3 were more difficult than set 1 [two-way ANOVAs, set 1 vs set $2, F(1,6)=11.87, p$ $=0.014$; set 1 vs set $3, F(1,6)=21.27, p=0.004]$.

For retention, a set $\times$ group interaction effect [two-way ANOVA, $F(2,12)=5.98, p=0.016]$ indicated that LES and CON monkeys differed in ability to remember particular concurrent discrimination problems: set 1 (stage B), CON $85.0 \% \pm 6.6 \%$, LES $89.2 \% \pm 2.2 \%$; set 1 (stage D), CON $92.7 \% \pm 2.6 \%$, LES $85.8 \% \pm 2.3 \%$; set 2 (stage D), CON $90.0 \% \pm 3.2 \%$, LES $83.2 \%$ $\pm 3.1 \%$. However, focused ANOVAs did not reveal any difference between groups (one-way ANOVAs, $p>0.05$ ) or within groups (one-way ANOVAs with repeated measures, $p>0.05$ ) for any of the concurrent discriminations.

\section{Discussion (behavioral series 1)}

Large basal forebrain lesions in monkeys had little effect on learning or memory for visual or spatial information, as measured by a large series of behavioral tasks. The effect of delays in the DNMS and DR tasks indicates that these tasks were sensitive to increasing demands on memory; therefore, the lack of behavioral impairments cannot be because of an insensitivity of these tasks to measure memory abilities.

Preoperative training may diminish cognitive impairments following lesions in monkeys (Chow and Survis, 1958; ZolaMorgan and Squire, 1986). Thus, in the present study, behavioral impairments in the LES monkeys may have been reduced by the preoperative training on the series of behavioral tasks, or by the extensive experience on these tasks. To test these hypotheses, a second series of behavioral tasks was administered

\section{Table 3. Behavioral series 2 order of testing}

Delayed nonmatch-to-sample $(0,30,60,120 \mathrm{sec}$ delays $)$

Delayed response $(0,10,30,60 \mathrm{sec}$ delays $)$

Delayed nonmatch-to-sample (lists of $3,5,10$; lists of $5,10,20$ )

Concurrent object discriminations (eight pairs)

Object discrimination reversals

Spatial discrimination reversals

to LES and CON monkeys. Series 2 contained several novel tests, and some behavioral tests of series 1 that were modified to include more difficult parameters or novel aspects.

\section{Behavioral series 2}

The following behavioral tests were examined 2-3 months after surgery (Fig. 1, stage E). The order of testing is listed in Table 3.

\section{Procedures}

DNMS with longer delays. A variable delay version of DNMS was again examined but this time with delays of $0,30,60$, and $120 \mathrm{sec}$. The procedure was identical to that of DNMS in series 1 , and 100 trials were given at each delay over three days.

DNMS with longer lists. The procedure was similar to that used in series 1 except that two groups of lists were examined: lists of 3, 5, and 10 objects; and lists of 5, 10, and 20 objects. Each group of lists was examined for two test sessions of 180 trials, for a total of 120 trials at each list length. Within a session, all list lengths of the group were randomly presented. For lists of 3,5 , and 10 , a session had 20 sets of 3,12 sets of 5 , and 6 sets of 10 . For lists of 5, 10, and 20, a session had 12 sets of 5 , 6 sets of 10 , and 3 sets of 20 . The dependent measure was choice accuracy at each list length.

$D R$. A variable delay version of DR was again examined with longer delays and the procedure was identical to that of DR in series 1 . Delays used were $0,10,30$, and $60 \mathrm{sec}$. Choice accuracy was examined for 100 trials per delay over $3 \mathrm{~d}$.

Concurrent object discriminations (eight pairs): acquisition and reversal. In this procedurc, eight novel pairs of objects werc presented on the side screens in 10 blocks of 8 trials each, for a daily session total of 80 trials. Thus, each object pair was seen once within each block and a total of 10 times within the daily test session. The order of the object pairs within each block and the left-right position of the objects were determined by a pseudorandom series and changed daily. A $15 \mathrm{sec}$ ITI followed correct responses, and a $35 \mathrm{sec}$ ITI followed incorrect responses. Acquisition criterion was a mean choice accuracy of at least $90 \%$ correct in one session of 80 trials. Sessions to criterion was the dependent measure. For reversal, reward contingencies of each pair of objects were the opposite of those during acquisition. Sessions to achieve a choice accuracy of at least $90 \%$ correct, in ore session of 80 trials, was the dependent measure.

Reversals of simple object discriminations. Two reversal experiments were conducted. The first experiment had four object discrimination problems with novel objects. Each object pair was presented for acquisition followed by one reversal, in which reward contingencies were the opposite of those during acquisition. The general procedure for acquisition and reversal was identical to that of acquisition of simple object discriminations in series 1 . Trials and errors to criterion were the dependent measures for both acquisition and reversal. 

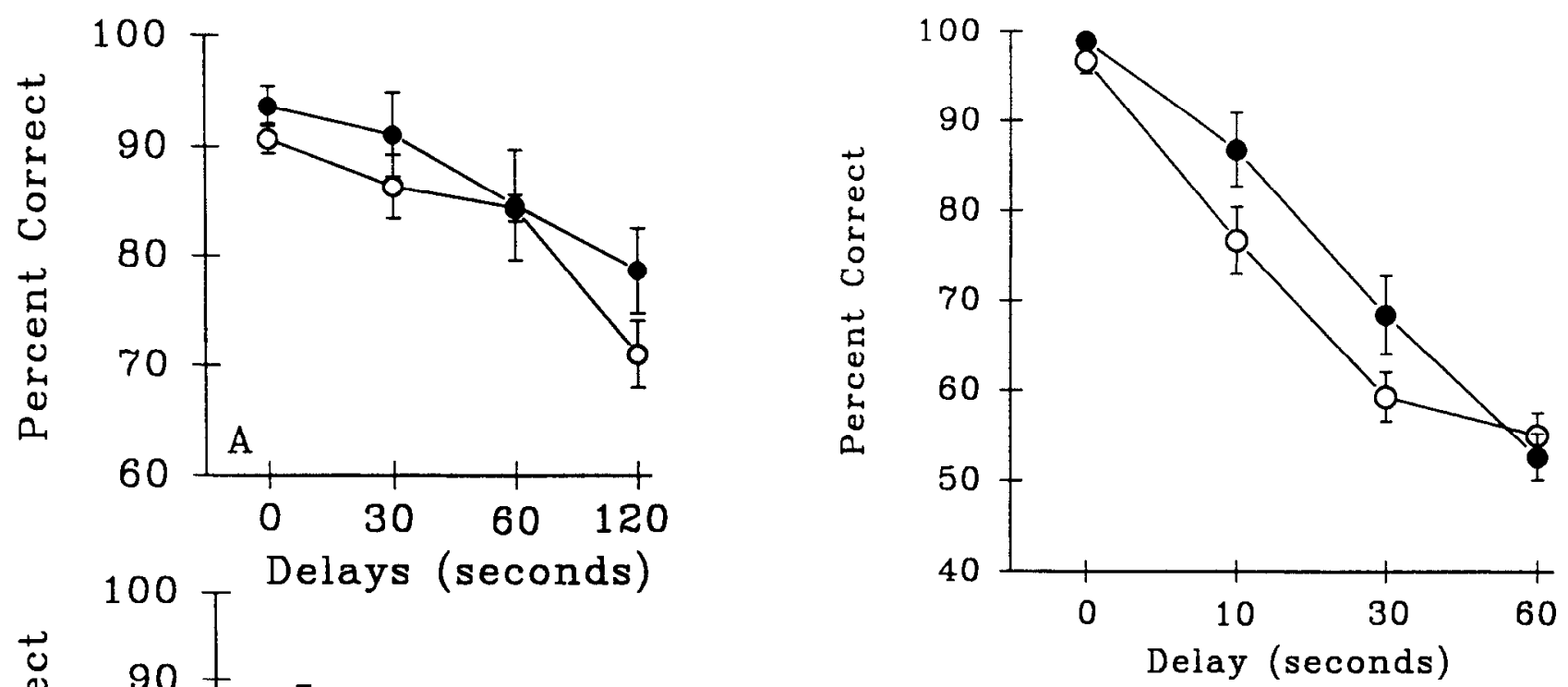

Figure 10. DR: behavioral series 2. Each delay was tested for 100 trials. Both groups were similar in performance on this task. Choice accuracy decreased as delays increased. Conventions are as in Figure 7.

same session. Similarly, more than one reversal could be administered within a daily session. Trials and errors to criterion were the dependent measures for acquisition and for each reversal.

Spatial discrimination: acquisition and reversals. At the start of a trial, homogeneous white light was projected onto the two side screens. Two responses to the left screen resulted in delivery of a reward for each response; responses to the right screen terminated the trial. The correct strategy on subsequent trials was to continue responding to the left screen. Following acquisition, six reversals were given. The general procedure for acquisition and reversal was identical to that of the object discrimination with six reversals described above.

\section{Results (behavioral series 2)}

$D N M S$ with longer delays. Choice accuracy for both groups was similar (two-way ANOVA, $p>0.05$ ) (Fig. $9 A$ ) and decreased as the delay interval increased $[F(3,18)=15.13, p<0.001]$, indicating greater difficulty with increasing delays.

$D N M S$ with longer lists. Choice accuracy on lists of 3,5 , and 10 objects was similar for both groups (two-way ANOVA, $p>$ $0.05)$ (Fig. $9 B)$, and decreased with longer list lengths $[F(2,12)$ $=16.86, p<0.001]$. Choice accuracy on lists of 5,10 , and 20 objects was similar for both groups (two-way ANOVA, $p>$ 0.05 ), and decreased with increasing list lengths (Fig. $9 C$ ) $[F(2,12)$ $=4.4, p=0.037]$.

$D R$. Choice accuracy was similar for LES and CON monkeys in DR (two-way ANOVA, $p>0.05$ ) (Fig. 10) and decreased as the delay increased $[F(3,18)=158.39, p<0.001]$.

Concurrent object discriminations (eight pairs). acquisition and reversal. LES monkeys were similar to CON monkeys in learning and reversing this version of concurrent object discriminations: acquisition sessions, CON $2.7 \pm 0.9$, LES $2.2 \pm 0.5$; reversal sessions, CON $3.3 \pm 2.3$, LES $4.2 \pm 1.2$. One-way ANOVAs indicated that CON and LES groups acquired and reversed these discriminations in a similar manner $(p>0.05)$.

Reversals of simple object discriminations. The first experiment examined the ability to acquire and perform a reversal of 
four different object discriminations. LES and CON monkeys acquired the four object discriminations at a similar rate, as measured by trials or errors to criterion: mean trials, CON 18.3 \pm 6.0 , LES $12.0 \pm 6.0$; mean errors, CON $3.4 \pm 0.9$, LES 2.6 \pm 1.0 (two-way ANOVAs, $p>0.05$ ). Both groups were similar in performing the reversal of each discrimination: mean trials, CON $35.0 \pm 11.5$, LES $29.0 \pm 9.4$; mean errors, CON $11.9 \pm$ 5.5 , LES $11.4 \pm 3.4$ (two-way ANOVAs, $p>0.05$ ).

The second experiment examined the ability to acquire an object discrimination and perform six reversals. As in the first experiment, LES monkeys learned at a similar rate to CON monkeys: trials, CON $20 \pm 11.5$, LES $16 \pm 7.5$; errors, CON $4.7 \pm 2.4$, LES $2.0 \pm 0.08$ (one-way ANOVA, $p>0.05$ for trials and errors), and performed six reversals comparable to CON monkeys: mean trials, CON $24.4 \pm 6.8$, LES $18.7 \pm 4.4$; mean errors, CON $6.9 \pm 2.4$, LES $5.6 \pm 1.5$ (two-way ANOVA, $p>0.05$ for trials or errors).

Spatial discrimination: acquisition and reversals. Both groups werc similar in acquiring a simple spatial discrimination: trials, CON $6.7 \pm 6.7$, LES $16.0 \pm 4.0$; errors, CON $1.7 \pm 1.7$, LES $4.2 \pm 1.3$ (one-way ANOVAs, $p>0.05$ ), and performing six reversals of a spatial discrimination: mean trials, CON $21.1 \pm$ 6.2 , LES $24.0 \pm 2.4$; errors, CON $6.1 \pm 2.6$, LES $6.0 \pm 1.1$ (two-way ANOVAs, $p>0.05$ ).

\section{Discussion (behavioral series 2)}

This second series of behavioral tests contained more difficult versions of the concurrent object discrimination, DNMS, and DR tasks. It also contained novel tasks of discrimination reversals and spatial discriminations. Lesions of the BFCS did not impair accuracy in these behavioral tasks. These findings suggest that the absence of large behavioral impairments in LES monkeys in series 1 was not because of preoperative training or extensive experience on those behavioral tests. Results from series 2 further support the behavioral findings from series 1; that is, BFCS lesions in monkeys do not produce large impairments in learning or memory as measured by an extensive series of behavioral tasks that assess a variety of cognitive abilities, with varying levels of performance difficulty and novelty.

If BFCS lesions in monkeys do not disrupt learning and memory, then what are the functions of neurons in the basal forebrain? Recent electrophysiological studies in monkeys suggest that the BFCS, particularly the NBM, may be more involved in attention or arousal mechanisms than memory per se (Sillito and Murphy, 1987; Buzsáki and Gage, 1991; Richardson and DeLong, 1991; Semba, 1991). Lesions of the BFCS disrupted attention in rodents (Olton et al., 1988; Robbins et al., 1989; Muir et al., 1992). Moreover, several cortical areas that receive cholinergic input from BFCS neurons also have a role in attention (Olton et al., 1988; Sato, 1988; Spitzer et al., 1988; Petersen et al., 1989). Therefore, to address this issue, an attention task was used that was adapted from a procedure used to examine spatial orienting of attention in human subjects with parietal lobe lesions (Posner et al., 1984, 1987) and patients with AD (Freed et al., 1989; Parasuraman et al., 1992).

\section{Attention task}

One CON monkey and two LES monkeys were prepared for histological examination before this experiment was initiated (but after the drug study; see below). Thus, the CON group contained two monkeys and the LES group contained three

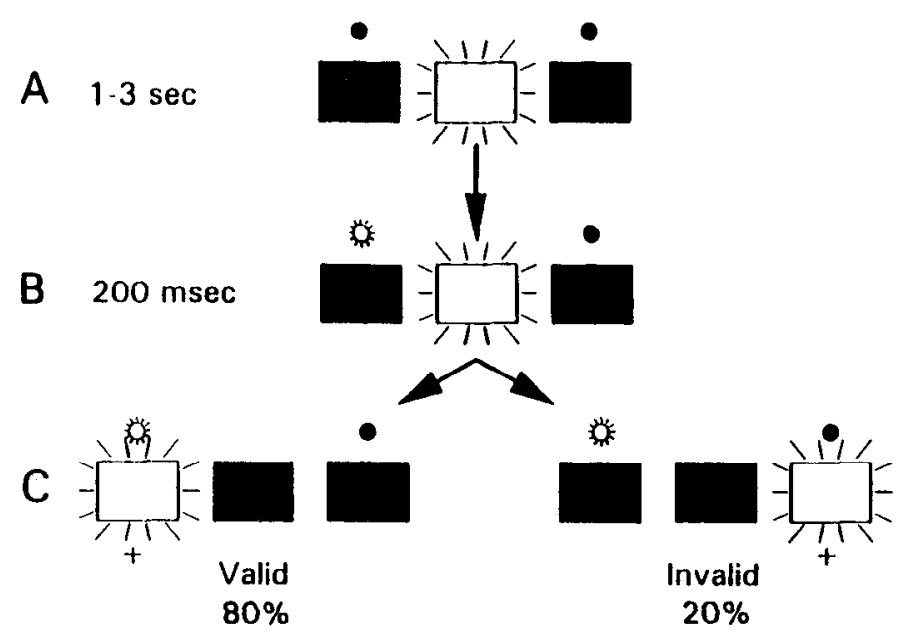

Figure 11. Attention task procedure. $A$, A trial began with depression of the illuminated center screen for a variable delay of $1-3$ sec. $B$, Depression of the illuminated center screen continued while one of the side cue lights was illuminated for $200 \mathrm{msec}$. $C$, The center screen was darkened and one of the side screens became illuminated as the target. The target could appear on the side corresponding to the illuminated cue light (valid trials) or on the opposite side of the illuminated cue light (invalid trials). In a test session, $80 \%$ of the trials were valid trials and $20 \%$ were invalid trials. In either type of trial, a reward was delivered for responding to the target (indicated by the "+")

monkeys for this experiment. Training on this task began 4-5 months after surgery (Fig. 1, stage F).

\section{Procedure}

The procedure was similar to that used with human subjects (Posner et al., 1987) (Fig. 11). At the start of a trial, a homogeneous white light appeared on the center screen. The monkey was required to continue depressing the lit center screen through a randomly chosen delay of $1-3 \mathrm{sec}$. At the end of the delay, one of two amber stimulus lights ("cue") above the side screens was illuminated for $200 \mathrm{msec}$, during which time the monkey continued to depress the center-lit screen. After $200 \mathrm{msec}$, the center screen was darkened, and one of the two side screens was illuminated with white light ("target"). Two types of target trials wcre possible. In valid trials, the target was presented on the same side as the cue. In invalid trials, the target was presented on the side opposite to that of the cue. In both valid and invalid trials, the correct strategy was to respond to the target to receive a reward. The target remained illuminated until a response was made to one of the screens. A $15 \mathrm{sec}$ ITI followed correct responses and a $35 \mathrm{sec}$ ITI followed incorrect responses. Daily sessions contained a maximum of 140 trials. In this task, the adjustable barrier used in the DR task was used to limit responses to only the preferred arm.

Training on the attention task began with trials in which no target appeared following the cue presentation (catch trials). To receive a reward on catch trials, the animal was required to depress the illuminated center screen until the trial ended 200 msec after the cue was presented. When an $85 \%$ level of accuracy was achieved in training sessions with only catch trials, valid and invalid trials were introduced with an ascending order of probability for valid trials until a session had $80 \%$ valid trials and $20 \%$ invalid trials. Testing took place for a total of 700 trials over 5-7 d. Dependent measures recorded for each trial were release time (the time to release the center screen once the 


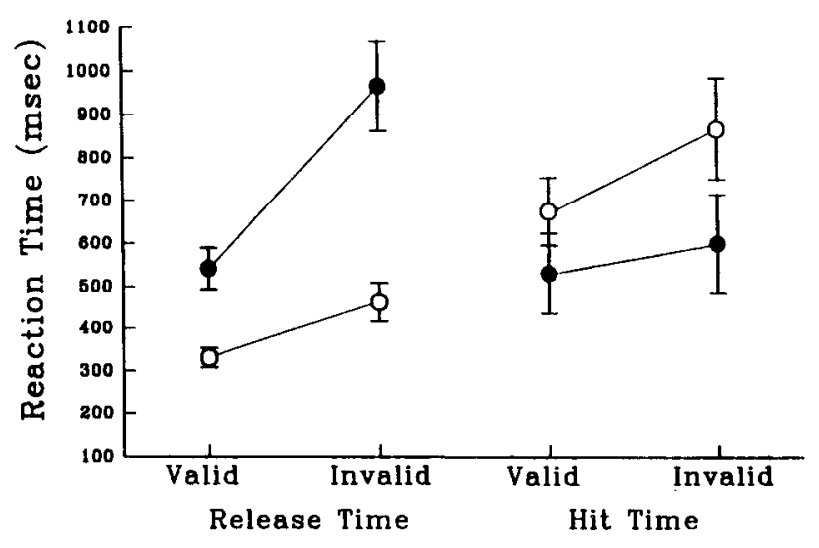

Figure 12. Release time and hit time in the attention task. A total of 700 trials was tested. Release time was faster at the appearance of the target on valid than invalid trials. LES monkeys were slower than CON in release time, particularly on invalid trials. Hit time was similar for both groups in valid and invalid trials, with no difference in hit time between valid and invalid trials. Conventions are as in Figure 7.

target appeared), hit time (the time to hit the target once the center was released), breaks (trials in which the lit center screen was released before the target appeared), and choice accuracy. The condition of the trial (valid or invalid) and the position of the target (left or right side screen) were also recorded for each trial.

\section{Results (attention task)}

Release time and hit time were not dependent upon the leftright position of the target on each trial (three-way ANOVA, $p$ $>0.05$ ), and the data have been collapsed across this measure for each of these factors. Release time was faster on valid than invalid trials (validity effects) [two-way ANOVA, $F(1,3)=20.67$, $p=0.02$ ] (Fig. 12). Release time was slower for LES monkeys than CON monkeys $[F(1,3)=16.53, p=0.027]$. The interaction of trial condition (valid or invalid) $\times$ group $[F(1,3)=5.72, p$ $=0.09]$ indicated that an effect may exist but the small number of subjects in this analysis did not provide the necessary power to provide a strong test of this effect. More focused analyses indicated that the LES group differed from the CON group in release time on invalid trials [one-way ANOVA, $F(1,3)=14.46$, $p=0.03$ ] but not on valid trials (one-way ANOVA, $p>0.05$ ). Hit time was comparable for both valid and invalid trials (twoway ANOVA, $p>0.05$ ), and both groups performed similarly for either type of trial $(p>0.05)$ (Fig. 12). Both groups of monkeys performed the final version of the attention task at $100 \%$ correct accuracy, and the LES monkeys made fewer breaks than CON monkeys [one-way ANOVA, $F(1,3)=12.44, p=$ 0.04].

\section{Discussion (attention task)}

In this attention task, the cue signaled the target location on $80 \%$ of the trials. Difference in speed of responding to a target at expected (valid trials) and unexpected (invalid trials) locations is a measure of shifting attention (Posner, 1980; Posner and Cohen, 1984; Posner et al., 1984). Slower response times on invalid trials, as compared to valid trials, indicate the validity effect. Comparable to normal human subjects, a validity effect was found in the present study, indicating that this procedure for monkeys is a good test of shifting attention.

Release time was slower in LES monkeys than CON monkeys.
The slower release time in LES monkeys was not caused by motor difficulties because hit time was comparable for both CON and LES monkeys. Although an interaction between trial condition and group did exist, this effect did not reach statistical significance at the 0.05 level. The focused analyses imply that a larger number of subjects may provide more power to detect this interaction reliably. Thus, the analyses of release time indicate that monkeys with BFCS lcsions have a gencral impairment in focused attention, and suggest that future investigations may detect specific impairments in shifting of attention. Similar impairments in attention have been described recently in patients with AD (Freed et al., 1989; Parasuraman et al., 1992). Moreover, significant improvement on other tests of attention has followed administration of cholinergic agonists in $\mathrm{AD}$ patients (Sahakian et al., 1989; Eagger et al., 1991). Thus, monkeys with BFCS lesions may be good models of some of the attention deficits observed in AD.

Several mental operations are proposed to be involved in the shifting of attention to a new spatial location (Posner et al., 1984, 1987). An increase in reaction time on invalid trials in humans with parietal lobe injury has been interpreted as a difficulty in disengaging attention from an expected target location (Posner et al., 1984). Although further experimentation is required, the results of the present study suggest that impairments in disengagement of attention may also result from BFCS lesions in monkeys.

\section{Relationships between lesion size, levels of ChAT, and behavior}

Although correlational analyses could not be performed because of the small number of subjects in the lesioned group, relationships between lesion size and levels of ChAT were found. Large BFCS lesions (LES-617, I.ES-003, LES-029) produced the lowest ChAT levels in cortical target fields. Relationships between lesion size, levels of ChAT, and behavior were not as clear. For example, LES-617 had a large BFCS lesion, some of the lowest cortical levels of ChAT, and performed the most poorly of all the lesioned monkeys across behavioral tasks. However, LES029 had a similar lesion and levels of ChAT, and yet had the best overall performance of the lesioned monkeys across behavioral tasks.

\section{Drug study}

To determine if BFCS lesions increased sensitivity to anticholinergic agents, CON $(N=3)$ and $\operatorname{LES}(N=5)$ monkeys received injections of the cholinergic antagonist scopolamine in an ascending and then discending dose-effect schedule over 3-5 months (Fig. 1, stage G). A DNMS task with list lengths of 1 , 5 , and 10 objects was used to evaluate the effects of scopolamine. An SNMS task was used to evaluate the effect of scopolamine on non-mnemonic abilities. $N$-methylscopolamine (NMS) was used to evaluate the contribution of peripheral cholinergic manipulation to the observed behavioral effects.

\section{Procedure}

Training and testing of DNMS with lists of 1,5 , and 10 objects followed the procedure for DNMS with lists of 3,5 , and 10 objects described in behavioral series 2. Test sessions had 180 trials (60 trials per list length per session). Training continued on this task until mean choice accuracy was approximately $90 \%$ at list length 1 (LL1), 80\% at list length 5 (LL5), and 70\% at list length 10 (LL10). Ascending and then descending dose-effect 

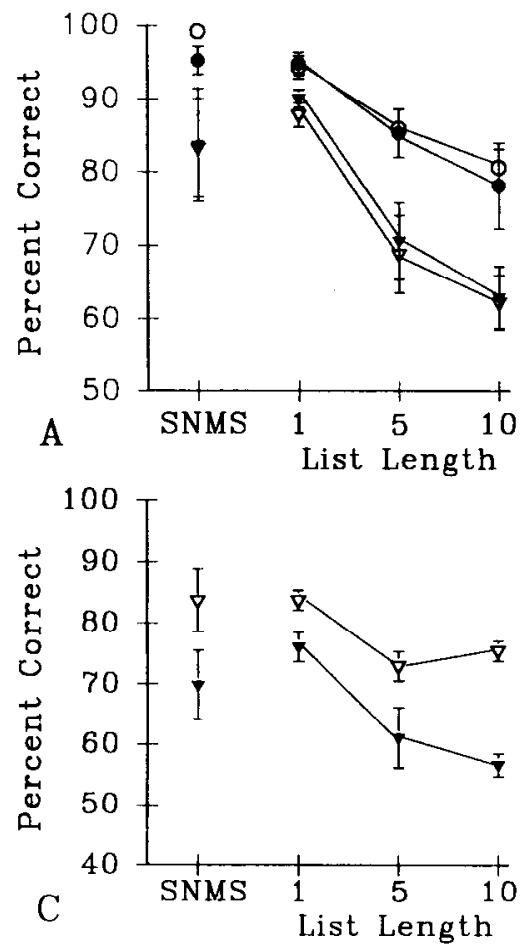
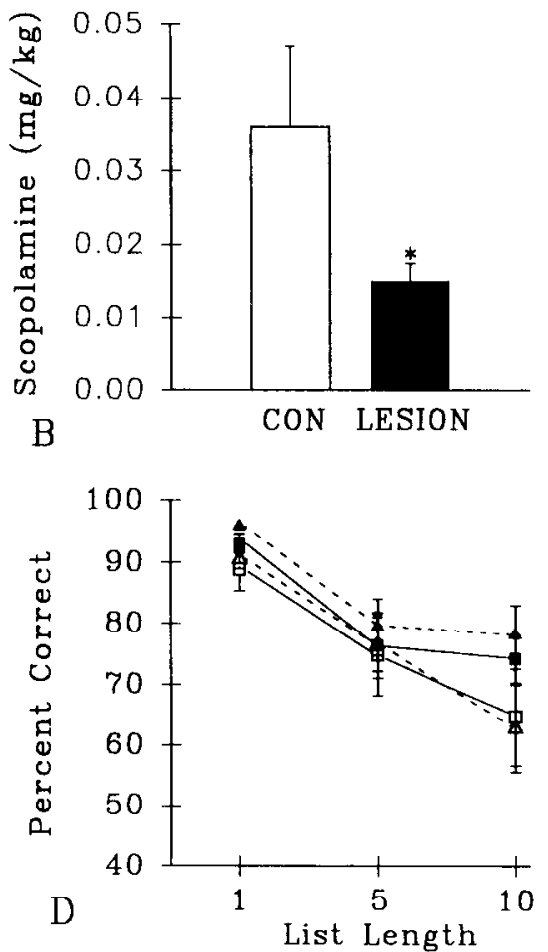

Figure 13. Scopolamine effects on an SNMS task and a DNMS task with list lengths of 1, 5, and 10 objects. $A$, Accuracy in the DNMS and SNMS tasks for CON and LES monkeys following injections of the most effective dose of scopolamine determined for each monkey. Most effective dose was that dose in which accuracy at list length 1 in the DNMS task was near $90 \%$ and accuracy at list lengths 5 and 10 was disrupted relative to predrug performance. $O$, predrug performance in CON monkeys; $\boldsymbol{\theta}$, predrug performance in LES monkeys; $\nabla$, scopolamine performance in CON monkeys; $\nabla$, scopolamine performance in LES monkeys. Error bars represent SEM. B, Bars represent the mean most effective dose of scopolamine in CON and LES monkeys that produced the graphs in $A$. LES monkeys required a significantly lower dose of scopolamine to achieve equivalent levels of accuracy in the DNMS task relative to CON monkeys. ${ }^{*}, p<0.01 . C$, DNMS and SNMS performance following injections of $0.04 \mathrm{mg} / \mathrm{kg}$ scopolamine. Accuracy on DNMS, but not SNMS, was significantly disrupted by the $0.04 \mathrm{mg} / \mathrm{kg}$ dose of scopolamine in LES relative to CON. Accuracy decreased with increasing list lengths in both groups. Conventions are as in $A$. $D$, Accuracy on DNMS was similar following control injections of $0.04 \mathrm{mg} / \mathrm{kg}$ of NMS or phosphate buffer. $\square$, CON buffer; $\triangle$, CON NMS; $\mathbf{\square}$, LES buffer; $\Delta$, LES NMS. Solid lines, buffer; Dashed lines, NMS.

curves were determined for scopolamine hydrobromide (Sigma, St. Louis, MO) (0.01-0.09 mg/kg; Scop.01-Scop.09) in the DNMS task. This study had two objectives: to determine the dose of scopolamine (termed "most effective dose") that allowed choice accuracy on LL1 of DNMS to remain at approximately $90 \%$ while lowering choice accuracy at LL5 and LL10 relative to the preceding noninjection day, and to compare accuracy between groups of monkeys on the DNMS task at several doses of scopolamine.

Following assessment on the DNMS task, training began on the SNMS task. At the start of a trial, an object appeared on the center screen as the sample. Ten responses to the center screen resulted in reward delivery and immediate initiation of the choice phase. In the choice phase, the sample object remained on the center screen and two objects also were projected onto the two side screens; one of these objects was identical to the sample object and the other object was a novel object. A correct response was to respond to the side screen containing the novel object. Two responses to the screen containing the novel object produced a reward for each response and initiated a $15 \mathrm{sec}$ ITI. A response to the side screen containing the same object as appeared on the center screen ended the trial and initiated a $35 \mathrm{sec}$ ITI. A session had 100 trials. Drug testing commenced once a mean choice accuracy of at least $90 \%$ correct in a session was achieved. An ascending and then descending dose-response curve was determined for scopolamine, and the doses of scopolamine ranged from $0.01 \mathrm{mg} / \mathrm{kg}$ to that dose that had been most effective in the DNMS task.

As control measures, injections of NMS (Sigma, St. Louis, MO) and phosphate buffer ( $\mathrm{pH} \mathrm{7.4)} \mathrm{were} \mathrm{used.} \mathrm{Doses} \mathrm{of} \mathrm{NMS}$ ranged from 0.02 to $0.04 \mathrm{mg} / \mathrm{kg}$ (NMS.02-NMS.04) in LES monkeys and from 0.04 to $0.09 \mathrm{mg} / \mathrm{kg}$ (NMS.04-NMS.09) in CON monkeys. These ranges were based on doses of scopolamine that disrupted DNMS performance in each group. If the behavioral effects of repeated doses were very different, then that dose was given a third time. All injections were given intramuscularly $30 \mathrm{~min}$ prior to the test session. At least one session without injections intervened between injection sessions.

\section{Results (drug study)}

Most effective dose. Figure 13 illustrates performance in the DNMS and SNMS tasks for CON and LES monkeys following drug injections. Figure $13 A$ presents the results for the most effective dose, that dose that disrupted choice accuracy on LL5 and LL10 in DNMS, relative to the preceding noninjection day, but left choice accuracy on LL1 at $90 \%$ correct. Data from LES456 and one CON monkey are not included in this data set because their performance on LL1 was affected at the lowest dose of scopolamine. Accuracy on DNMS was similar for both groups of monkeys on noninjection days preceding the most effective dose (two-way ANOVA, $p>0.05$ ), and accuracy de- 
creased with increasing list lengths $[F(2,8)=14.42, p=0.002]$. LES and CON monkeys performed at comparable levels of accuracy on DNMS following injection with the most effective dose determined for each monkey (two-way ANOVA, $p>0.05$ ), and performance decreased with increasing list lengths $[F(2,8)$ $=44.33, p<0.001]$. Both groups of monkeys performed more poorly following the most effective dose compared to the noninjection day [three-way ANOVA, $F(1,4)=172.77, p<0.001$ ].

Accuracy on the SNMS task was comparable between groups on noninjection days and following injections with the most effective dose (two-way ANOVA, $p>0.05$ ), and accuracy was not disrupted by injections of the most effective dose $(p>0.05)$. Furthermore, accuracy on the SNMS task and LL1 of the DNMS task was similar for both LES and CON monkeys following injection with the most effective dose (two-way ANOVA, $p>$ $0.05)$.

With performance on DNMS equated between groups, LES monkeys were more sensitive to scopolamine than CON monkeys in that, in LES monkeys, a lower dose of scopolamine was needed to produce equivalent levels of DNMS performance to CON monkeys following injections with higher doses of scopolamine [one-way ANOVA, $F(1,4)=65.33, p=0.001$ ] (Fig. $13 B)$.

Comparison across doses. Data from all LES and CON monkeys were included in the data sets for these analyses. For Scop.02-Scop.04, LES monkeys were different from CON monkeys in performing the DNMS task only with Scop.04 [two-way ANOVA, $F(1,6)=13.00, p=0.011]$. DNMS and SNMS accuracy following Scop.04 in LES and CON monkeys is illustrated in Figure $13 \mathrm{C}$. Scop.04 produced a greater effect with increasing list lengths $[F(2,12)=16.87, p<0.001]$, but there was no interaction of this effect with group $(p>0.05)$. LES and CON monkeys were not reliably different in choice accuracy on the SNMS task following Scop.04 (two-way ANOVA, $p>0.05$ ) (Fig. 13C), and accuracy on SNMS was similar to accuracy on LL1 of DNMS for both groups at this dose (two-way ANOVA, $p>0.05$ ).

Control injections of $0.04 \mathrm{mg} / \mathrm{kg}$ of NMS or phosphate buffer affected DNMS comparably in both groups (three-way ANOVA, $p>0.05$ ) (Fig. 13D). In comparing accuracy on the DNMS task following injections of Scop.04 or NMS.04, a drug $\times$ group effect was found [three-way ANOVA, $F(1,6)=7.88, p=0.03$ ]. Repeated-measures analyses revealed that accuracy on the DNMS task for LES monkeys at Scop.04 was worse than following injections of NMS.04 [two-way ANOVA, $F(1,4)=15.8$, $p=0.016$ ], whereas CON monkeys performed similarly following injections of Scop.04 or NMS.04 (two-way ANOVA, $p>$ 0.05 ). Scop. 04 reduced accuracy on SNMS relative to NMS.04 in LES and CON monkeys [two-way $\Lambda$ NOVA, $F(1,6)=17.09$, $p=0.006]$.

In comparing accuracy on DNMS following injections of Scop.04 or phosphate buffer, there was a drug $\times$ group effect [three-way ANOVA, $F(1,6)=6.35, p=0.04$ ]. Further analyses found that LES monkeys performed worse following Scop.04 than buffer on DNMS [repeated-measures two-way ANOVA, $F(1,4)=14.47, p=0.019]$, whereas CON monkeys performed comparably following either injection (repeated-measures twoway ANOVA, $p>0.05$ ).

\section{Discussion (drug study)}

Response to injections of scopolamine in LES monkeys provides further evidence that the neurotoxic injections in the BFCS severely compromised the central cholinergic system in these animals. The responses to scopolamine were caused by effects on central cholinergic mechanisms becausc comparable injections of NMS did not produce the same responses.

Two measures of reactions to scopolamine indicated the increased sensitivity of the LES group. First, LES monkeys were more sensitive to injections of scopolamine than CON monkeys as seen when DNMS performance was equated between groups of monkeys. In this instance, half the dose was required by LES monkeys to produce the same impairment as CON monkeys. Second, the magnitude of impairment in response to Scop.04 was greater in the LES group than in the CON group. This increased sensitivity in monkeys with BFCS lesions mimics the enhanced sensitivity observed in AD patients with scopolamine challenges (Sunderland et al., 1985a,b).

Scopolamine did not impair differentially SNMS or LL1 of DNMS in LES and CON monkeys. The SNMS task and LL1 of DNMS do not place strong demands on memory processes and, thus, provide a measure of non-mnemonic functions. Comparable effects of scopolamine in LES and CON monkeys in these two situations indicate that non-mnemonic processes were not more affected in LES than CON monkeys.

\section{General Discussion}

The present study is the most systematic examination of the bchavioral effects of BFCS lesions in monkeys to date. As noted in the following points, the behavioral tasks were chosen because of their maximal expected sensitivity to the functional effects of the BFCS lesions. First, in monkeys, performance in these tasks is impaired following lesions of the BFCS projection targets: prefrontal (Goldman and Rosvold, 1970; Mahut, 1971; Bauer and Fuster, 1976; Voytko, 1985; Bachevalier and Mishkin, 1986), parietal (Petersen and Robinson, 1986), and temporal (Cowey and Gross, 1970; Mishkin, 1982; Horel et al., 1984, 1987; Voytko, 1986; Phillips et al., 1988; George et al., 1989; Zola-Morgan et al., 1989b; Gaffan and Murray, 1992) cortices, and hippocampus (Mahut, 1971; Squire and Zola-Morgan, 1991). If projections from neurons in the BFCS to these target sites are necessary for their functional integrity, then lesions of BFCS neurons might be expected to produce a pattern of behavioral impairments similar to those following lesions of the target sites, as is the case in rodents (Olton and Wenk, 1987; Kesner and Johnson 1991; Olton et al., 1991a,b). Second, in rats, performance in similar tasks was impaired following lesions of the BFCS (Olton and Wenk, 1987; Olton et al., 199 la,b). If the primate BFCS mediates behavioral functions similar to those in rodents, then lesions of the primate BFCS should impair performance in these tasks. Third, the initial postoperative testing period was completed quickly, in only 6 weeks. Although recovery of function has sometimes followed extensive behavioral testing after BFCS lesions (Ridley et al., 1986; Roberts et al., 1990; Aigner et al., 1991), the rapid postoperative testing in many different behavioral procedures in series 1 in the present study minimized the influence of any possible postoperative recovery. Fourth, the level of task demand was manipulated so that choice accuracy of control monkeys had a wide range, from almost perfect to near chance. Consequently, the task parameters avoided the constraints of both "ceiling effects" (performance so good that lesions cannot disrupt function enough to produce an impairment) and "floor effects" (performance so poor that lesions are unable to reduce it further). Fifth, many different psychological functions were assessed by the tasks: re- 
cent memory for visual stimuli (DNMS), recent memory for spatial location (DR), long-term memory for object-reward associations (simple object discriminations), interference in longterm memory (concurrent object discriminations), and focusing and shifting of attention (attention task). If the BFCS lesions in the present study impaired cognitive function, then this set of behavioral tasks should be sufficient to detect it. Sixth, scopolamine, a drug that blocks cholinergic function and impairs choice accuracy in tests of recent memory, such as DNMS, was used to determine if the BFCS lesions increased the sensitivity to blockade of the cholinergic system. Increased sensitivity to scopolamine can be an indication of the functional effectiveness of the lesion.

\section{BFCS and memory}

In the context of the experimental design outlined above, the absence of behavioral impairments in most of the tests of learning and memory is striking. In both series 1 , given immediately after surgery, and in series 2 , with more difficult versions of the tasks, monkeys with BFCS lesions performed similarly to controls. These findings are especially impressive given the substantially increased sensitivity of the lesioned monkeys to scopolamine; evidence that the central cholinergic system was severely compromiscd in these animals.

The lack of impaired memory following the BFCS lesions may be caused by a variety of factors: the size of the lesion, the functional effects of the lesion on the cholinergic system, and the species of animal being tested. Each of these points will be considered in turn.

Lesions of the BFCS were substantial but not complete. In other experiments, the magnitude and duration of the behavioral impairment, following disruption of the BFCS, depended on the size of the lesion. For example, recent memory in rats was impaired by lesions of the fimbria-fornix (Raffaele and Olton, 1988) that severed projections from the medial septal area to the hippocampus, and by direct infusions of drugs (muscimol, scopolamine) into the medial septal area to inhibit the activity of those cells (Givens and Olton, 1990; Olton et al., 1991c). Partial lesions of the fimbria-fornix and lower drug doses produced mnemonic impairments that were smaller in magnitude and shorter in duration than larger lesions and higher drug doses. The exact form of the function relating the size of the BFCS lesion to the magnitude of the behavioral impairment in mnemonic tasks has not yet been examined, and this information is critical to reach a final conclusion. For example, some systems are organized with so much plasticity that little, if any, behavioral impairment occurs until the lesion includes more than $90 \%$ of the system (Olton, 1991). The increased sensitivity of BFCS monkeys to injections of scopolamine, as reflected in a lower effective dose in the DNMS task, suggests that a larger lesion might have produced a differential impairment. However, such a lesion is impractical with the current methodology; even the lesions here, produced in two stages, resulted in a profound postoperative syndrome that required careful monitoring and treatment. As summarized previously, the absence of a behavioral impairment in the current experimental procedures is striking, especially given the substantial impairments that occur in rodents with lesions of similar size.

Other lines of evidence suggest that lesion size was not the critical factor. First, mnemonic impairments were found with considerably smaller lesions of the BFCS in New World monkeys (Ridley et al., 1985, 1988a; Irle and Markowitsch, 1987).
Moreover, recent studies in rodents have shown that the degree of memory impairment following neurotoxic lesions of the BFCS was not related to the extent of cholinergic cell loss (Robbins et al., 1989; Connor et al., 1991; Riekkinen et al., 1991; Wenk et al., 1992). Second, monkeys with BFCS lesions in the present study had decreases in cortical ChAT levels that were comparable to the decreases in ChAT reported in similar cortical regions in AD patients (Rossor et al., 1982; Wilcock et al., 1982; Bird et al., 1983; Bowen et al., 1983; Henke and Lange, 1983; Koshimura et al., 1986). Third, although not all BFCS neurons were destroyed by the neurotoxic injections in monkeys with BFCS lesions, the magnitude of destruction was comparable to that in cases of AD (Perry et al., 1982; Arendt et al., 1983; Rinne et al., 1987; Wilcock et al., 1988; Vogels et al., 1990; Iraizoz et al., 1991).

Another possible explanation for the absence of memory deficits may be the topography of the BFCS lesion. Damage in the MS and NDBB was small, and because these components of the BFCS send cholinergic projections to hippocampus, mnemonic abilities might be spared because limited lesions of the MS/NDBB did not significantly interfere with hippocampal functions important for cognitive processes. Although this line of reasoning has some merit, several points need to be considered. First, the relationship between the extent of damage in the MS/NDBB and the functional integrity of the hippocampus is not clear. Recent studies that have compared the behavioral effects of ibotenic or quisqualic acid lesions of the BFCS in rodents have shown that the degree of memory impairment was not related to the extent of cholinergic cell loss (Robbins et al., 1989; Connor et al., 1991; Riekkinen et al., 1991; Wenk et al., 1992) or activity of surviving cholinergic neurons (Wenk et al., 1992). Second, in AD, although hippocampal function is likely to be compromised severely by the significant pathology observed in this structure, the relationship between the extent of pathology in the hippocampus and in the MS/NDBB in this disease also remains unclear. For example, neuronal numbers in the MS/NDBB were unaltered in some patients with $\mathrm{AD}$ (Wilcock et al., 1988; Vogels et al., 1990). Third, a similar relationship to that presented for MS/NDBB and hippocampus could be applied to the NBM and cortex. If cortex depends upon cholinergic input for cortical functions related to mnemonic abilities, then the substantial damage in the NBM surely should have disrupted mnemonic processes that depend upon the integrity of several cortical areas. For example, lesions in inferior temporal cortex or parahippocampal gyrus impaired accuracy on DNMS (Mishkin, 1982; Horel et al., 1987; George et al., 1989; Zola-Morgan et al., 1989b), and similar lesions in dorsolateral prefrontal cortex impaired accuracy on DR (Goldman and Rosvold, 1970; Bauer and Fuster, 1976), at the delays used in the present study.

An alternative explanation of the absence of memory impairments in cynomolgus monkeys with BFCS lesions is that cholinergic input alone may not be necessary for mediation of mnemonic function by the targets of BFCS neurons. This independence of mnemonic function from cholinergic input would be different from that found in New World monkeys. The majority of studies using New World monkeys used the common marmoset (Callithrix jacchus) or the common squirrel monkey (Saimiri sciureus). In these studies, ibotenic acid or NMDA injections were made in the NDBB or the NBM. Visual discriminations and DNMS were impaired with lesions of the NBM (Ridley et al., 1985, 1988a; Irle and Markowitsch, 1987; Roberts 
et al., 1992), whereas visuospatial discriminations were impaired with lesions of the NDBB (Ridley et al., 1988b, 1989).

In contrast to BFCS lesions in New World monkeys, similar lesions in Old World monkeys have produced, at best, only mildly transient memory deficits. In cynomolgus monkeys, combined lesions of the MS and NDBB (Aigner et al., 1991), or lesions limited to only the NBM (Aigner et al., 1987), did not disrupt visual recognition memory, as measured by DNMS (Aigner et al., 1987, 1991) or delayed recognition memory span (Beason et al., 1990). Combined damage to all three regions of the BFCS in monkeys impaired DNMS (Aigner et al., 1991), but task difficulty did not disproportionately affect choice accuracy, suggesting that memory processes per se were spared. Moreover, this general impairment was transient, with recovery occurring within 3-4 months. Taken together, the results from the present study, and previous studies using Old World monkeys, indicate that substantial lesions of the BFCS do not produce severely compromising or long-lasting effects on learning and memory.

The reasons for the different results following BFCS lesions in rats, New World monkeys, and Old World monkeys are not obvious and may involve both cholinergic and noncholinergic mechanisms. Complete lesions of the target structures (hippocampus for MS and cortex for NBM) in rats, monkeys, and humans all produce substantial and reliable changes in behavior. However, the magnitude of behavioral effects following similar lesions in rats and monkeys can vary. For example, in relevant comparative studies, the behavioral effects of fornix lesions that disrupt the projections from the MS to the hippocampus were compared in equivalent tasks in both rats and monkeys (Markowska et al., 1989; Murray et al., 1989). For both species, the lesion produced a significant impairment in working memory as assessed by delayed alternation in a T-maze. However, the magnitude of the effect was greater in rats than in monkeys. Thus, for a given lesion in the BFCS, rats may show a greater behavioral impairment than monkeys. The implications of this result for comparative analyses of the neural circuits that underlie cognitive function require further experimentation, using the kinds of strategies that test the animals in tasks that are as similar as possible.

\section{BFCS and attention}

In the present study, attentional processes were disrupted by the BFCS lesions. Studies in rodents and humans also have shown that the BFCS modulates attention. Rats with NBM lesions were unable to divide attention between two simultaneously presented stimuli (Olton et al., 1988), or to localize briefly presented visual targets (Robbins et al., 1989; Muir et al., 1992), although general sensory functions remained intact. Infusions of muscimol, a GABA agonist, into the NBM slowed reaction time and altered discriminability in a two-choice reaction time task, suggesting that the NBM may be involved in attention (Pang et al., 1993). Pharmacological studies also have shown that the cholinergic system is involved in attention in normal people (Wesnes and Warburton, 1983; Dunne and Hartley, 1985) and in patients with $\Lambda \mathrm{D}$ (Sunderland et al., 1985a,b; Sahakian et al., 1989; Eagger et al., 1991). Furthermore, electrophysiological studies have indicated that the BFCS is involved in cortical activation and arousal (reviewed in Buzsáki and Gage, 1991; Richardson and DeLong, 1991; Semba, 1991), one behavioral correlate of which may be attention (Dunnett et al., 1991).

Attentional functions also have been posited in frontai (Stuss and Benson, 1986; Olton et al., 1988; Petersen et al., 1991), parietal (Posner et al., 1982; Mesulam, 1983; Heilman and Valenstein, 1985; Petersen and Robinson, 1986; Robinson et al., 1991), and temporal (Sato, 1988; Spitzer et al., 1988; Fuster, 1990) cortices, and some attentional deficits following cortical lesions are similar to those following BFCS lesions. For example, lesions in frontal cortex or NBM similarly disrupted performance on a divided attention task (Olton et al., 1988). In the present study, slower reaction times to stimuli, especially ones that appeared in unexpected locations, mimic to some extent the difficulties that patients with parietal lobe injury display on a similar attention task (Posner et al., 1984). Because the BFCS provides the major cholinergic innervation to cortex, the BFCS and cortex may share some features of attention processing (Olton and Pang, 1992).

Disruption of attention might contribute to impairments in learning and memory. However, in the present study, lesions of the BFCS in monkeys did not disrupt learning or memory per se, but did alter attention. One explanation for these findings may lie in the types of learning and memory tasks that were used. These tasks were chosen because they are sensitive to learning and memory impairments produced by a variety of manipulations. These behavioral tasks may not be sensitive or selective for detecting impairments in attentional processes that may not be severe enough to interfere with learning and memory abilities assessed by these tasks. However, with more formal and directed assessments of attention, limitations in attention capabilities following BFCS lesions become apparent.

\section{$B F C S$ and $A D$}

Pathology in the BHCS is a prominent feature of AD, and it may be responsible for the severe memory deficits observed in these patients (Bartus ct al., 1982; Price et al., 1982; Coyle et al., 1983). However, the results of the present study, in combination with data from clinical investigations, make it difficult to accept completely the hypothesis that BFCS degeneration is a necessary prerequisite for the memory deficits associated with AD. As noted earlier, monkeys with lesions had BFCS damage, and increased sensitivity to the cholinergic antagonist scopolamine, which mimics the BFCS degeneration and sensitivity observed in $\mathrm{AD}$, but these monkeys did not have impairments in memory. Similarly, patients with olivopontocerebellar atrophy (Kish et al., 1988, 1989) or Parkinson's disease (Candy et al., 1983; Dubois et al., 1983; Tagliavini et al., 1984; Mufson and Kordower, 1989) can have marked reductions in markers of the BFCS but not exhibit signs of dementia. Conversely, cholinergic markers can be relatively unaffected in cases of senile dementia or Pick's disease (Tagliavini and Pilleri, 1983), or in some individuals with clinical dementia and the histopathology of AD (Palmer et al., 1986). These findings in monkeys and humans raise interesting questions regarding the basis of memory deficits in AD and the functions of the primate BFCS in general.

Cognitive impairments associated with $\mathrm{AD}$ include various types of attention (Capitani et al., 1988; Freed et al., 1989; Grady et al., 1989; Haxby ct al., 1991; Mueller et al., 1991; Spinnler, 1991). The present study suggests that BFCS damage may contribute to impairments in attention observed in these individuals. Thus, monkeys with BFCS lesions may be good models of the attention deficits observed in individuals with AD. Additional investigations of this animal model will serve to delineate the spectrum of attention deficits that follow BFCS lesions 
in monkeys and determine the extent to which attention deficits in these monkeys mimic attention deficits in AD.

Correspondingly, AD is not solely a disease of the cholinergic system. These patients have significant abnormalities in a variety of cortical and subcortical regions (Adolfsson et al., 1979; Bondareff et al., 1982; Kemper, 1984; Yamamoto and Hirano, 1985; Beal et al., 1986; Rossor and Iversen, 1986; Beal and Marzurek, 1987; Palmer et al., 1987; Greenamyre and Young, 1989; Marcyniuk et al., 1989; Gottfries, 1990; Scheff et al., 1990; Arnold et al., 1991; Price et al., 1991). Memory deficits in AD may be the result of the substantial pathology found in cortical areas of these individuals. Alternatively, concurrent dysfunction of cholinergic and noncholinergic systems, alone or in combination with cortical degeneration, may be responsible for memory impairments in $\mathrm{AD}$. Although this latter hypothesis has been proposed for some time, it has been overshadowed by the focus on the cholinergic system, and relatively few animal studies have been directed at assessing its validity. A recent review of this literature by Decker and McGaugh (1991) indicates that successful behavioral performance may depend upon functional interactions between cholinergic and noncholinergic systems. Studies with rodent models have demonstrated that combined disruption of cholinergic and serotonergic (Vanderwolf, 1987; Nilsson et al., 1988; Richter-Levin and Segal, 1989; Riekkinen et al., 1990) or noradrenergic (Decker and Gallagher, 1987; Decker et al., 1990) systems produce larger memory deficits than either condition alone. These behavioral findings gain support from another setting involving mechanisms of neural plasticity. In a study investigating plasticity in visual cortex, Bear and Singer (1986) demonstrated that disruption of cholinergic input alone did not prevent reorganization of ocular dominance columns in kitten striate cortex. However, combined interruption of the cholinergic and noradrenergic systems did disrupt this plasticity. Compensatory mechanisms of this type also were speculated to have played a role in the transient behavioral deficits following BFCS lesions in cynomolgus monkeys (Aigner et al., 1991). These behavioral and anatomical data propose that one approach, for further investigations of primate models of the cognitive impairments reported in $\mathrm{AD}$, be directed toward morc systcmatically investigating functional interactions between cholinergic and noncholinergic systems that are affected in this neurodegenerative disease.

\section{References}

Adolfsson R, Gottfries CG, Roos BE, Winblad B (1979) Changes in the brain catecholamines in patients with dementia of Alzheimer type. Br J Psychiatry 135:216-223.

Aigner TG, Mishkin M (1986) The effects of physostigmine and scopolamine on recognition memory in monkeys. Behav Neural Biol 45: 81-87.

Aigner TG, Mitchell SJ, Aggleton JP, DeLong MR, Struble RG, Price DL, Wenk GL, Mishkin M (1987) Effects of scopolamine and physostigmine on recognition memory in monkeys with ibotenic-acid lesions of the nucleus basalis of Meynert. Psychopharmacology 92: 292-300.

Aigner TG, Mitchell SJ, Aggleton JP, DeLong MR, Struble RG, Price DL, Wenk GL, Pettigrew KD, Mishkin M (1991) Transient impairment of recognition memory following ibotenic-acid lesions of the basal forebrain in macaques. Exp Brain Res 86:18-26.

Arendt T, Bigl V, Arendt A, Tennstedt A (1983) Loss of neurons in the nucleus basalis of Meynert in Alzheimer's disease, paralysis agitans and Korsakoff's disease. Acta Neuropathol (Berl) 61:101-108.

Arnold SE, Hyman BT, Flory J, Damasio AR, Van Hoesen GW (1991) The topographical and neuroanatomical distribution of neurofibrillary tangles and neuritic plaques in the cerebral cortex of patients with Alzheimer's disease. Cereb Cortex 1:103-116.
Bachevalicr J, Mishkin M (1986) Visual recognition impairment follows ventromedial but not dorsolateral prefrontal lesions in monkeys. Behav Brain Res 20:249-261.

Bartus RT (1978) Evidence for a direct cholinergic involvement in the scopolamine-induced amnesia in monkeys: effects of concurrent administration of physostigmine and methylphenidate with scopolamine. Pharmacol Biochem Behav 9:833-836.

Bartus RT (1982) Effects of cholinergic agents on learning and memory in animal models of aging. In: Aging, Vol 19, Alzheimer's disease: a report of progress in research (Corkin S, Growdon JH, Davis KL, Usdin E, Wurtman RJ, eds), pp 271-280. New York: Raven.

Bartus RT, Johnson HR (1976) Short-term memory in the rhesus monkey: disruption from the anti-cholinergic scopolamine. Pharmacol Biochem Behav 5:39-46.

Bartus RT, Dean RL, Beer B, Lippa AS (1982) The cholinergic hypothesis of geriatric memory dysfunction. Science 217:408-417.

Bauer RH, Fuster JM (1976) Delayed-matching and delayed-response deficit from cooling dorsolateral prefrontal cortex in monkeys. J Comp Physiol Psychol 90:293-302.

Beal MF, Mazurek MF (1987) Substance P-like immunoreactivity is reduced in Alzheimer's disease cerebral cortex. Neurology 37:12051209.

Beal MF, Mazurek MF, Chattha GK, Svendsen CV, Bird ED, Martin JB (1986) Neuropeptide $Y$ immunoreactivity is reduced in cerebral cortex in Alzheimer's disease. Ann Neurol 20:282-288.

Bear MF, Singer W (1986) Modulation of visual cortical plasticity by acetylcholine and noradrenaline. Nature 320:172-176.

Beason LL, Moss MB, Rosene DL (1990) Effects of entorhinal, parahippocampal, or basal forebrain lesions on recognition memory in the monkey. Soc Neurosci Abstr 16:617.

Bird TD, Stranahan S, Sumi SM, Raskind M (1983) Alzheimer's disease: choline acetyltransferase activity in brain tissue from clinical and pathological subgroups. Ann Neurol 14:284-293.

Bondareff W, Mountjoy CQ, Roth M (1982) Loss of neurons of origin of the adrenergic projection to cerebral cortex (nucleus locus ceruleus) in senile dementia. Neurology 32:164-168.

Bowen DM, Allen SJ, Benton JS, Goodhardt MJ, Haan EA, Palmer AM, Sims NR, Smith CCT, Spillane JA, Esiri MM, Neary D, Snowdon JS, Wilcock GK, Davison AN (1983) Biochemical assessment of serotonergic and cholinergic dysfunction and cerebral atrophy in Alzheimer's disease. J Neurochem 41:266-272.

Buzsáki G, Gage FH (1991) Role of the basal forebrain cholinergic system in cortical activation and arousal. In: Activation to acquisition. Functional aspects of the basal forebrain cholinergic system (Richardson RT, ed), pp 115-133. Boston: Birkhäuser.

Candy JM, Perry RH, Perry EK, Irving D, Blessed G, Fairbairn AF, Tomlinson BE (1983) Pathological changes in the nucleus of Meynert in Alzheimer's and Parkinson's diseases. J Neurol Sci 54:277289.

Capitani E, Della Sala S, Lucchelli F, Soave P, Spinnler H (1988) Perceptual attention in aging and dementia measured by Gottschaldt's hidden figure test. J Gerontol 43:P157-P163.

Chow KL, Survis J (1958) Retention of overlearned visual habit after temporal cortical ablation in monkey. AMA Arch Neurol Psychiatry 79:640-646.

Connor DJ, Langlais PJ, Thal LJ (1991) Behavioral impairments after lesions of the nucleus basalis by ibotenic acid and quisqualic acid. Brain Res 555:84-90.

Cowey A, Gross CG (1970) Effects of foveal prestriate and inferotemporal lesions on visual discrimination by rhesus monkeys. Exp Brain Res 11:128-144.

Coyle JT, Price DL, DeLong MR (1983) Alzheimer's disease: a disorder of cortical cholinergic innervation. Science 219:1184-1 190.

Decker MW, Gallagher M (1987) Scopolamine-disruption of radial arm maze performance: modification by noradrenergic depletion. Brain Res 417:59-69.

Decker MW, McGaugh JL (1991) The role of interactions between the cholinergic system and other neuromodulatory systerns in learning and memory. Synapse 7:151-168.

Decker MW, Gill TM, McGaugh JL (1990) Concurrent muscarinic and $\beta$-adrenergic blockade in rats impairs place-learning in a water maze and retention of inhibitory avoidance. Brain Res 513:81-85.

Détári L, Vanderwolf CH (1987) Activity of identified cortically projecting and other basal forebrain neurones during large slow waves and cortical activation in anaesthetized rats. Brain Res 437:1-8. 
Drachman DA (1981) The cholinergic system, memory, and aging. In: Aging, Vol 17, Brain neurotransmitters and receptors in aging and age-related disorders (Enna SJ, Samorajski T, Beer B, eds), pp 255268. New York: Raven.

Dubois B, Ruberg M, Javoy-Agid F, Ploska A, Agid Y (1983) A subcortico-cortical cholinergic system is affected in Parkinson's disease. Brain Res 288:213-218.

Dunne MP, Hartley LR (1985) The effects of scopolamine upon verbal memory: evidence for an attentional hypothesis. Acta Psychol 58: 205-217.

Dunnett SB, Everitt BJ, Robbins TW (1991) The basal forebraincortical cholinergic system: interpreting the functional consequences of excitotoxic lesions. Trends Neurosci 14:494-501.

Eagger SA, Levy R, Sahakian BJ (1991) Tacrine in Alzheimer's disease. Lancet 337:989-992.

Flynn DD, Weinstein DA, Mash DC (1991) Loss of high-affinity agonist binding to M1 muscarinic receptors in Alzheimer's disease: implications for the failure of cholinergic replacement therapies. Ann Neurol 29:256-262.

Fonnum F (1969) Radiochemical micro assays for the determination of choline acetyltransferase and acetylcholinesterase activities. Biochem J 115:465-472.

Freed DM, Corkin S, Growdon JH, Nissen MJ (1989) Selective attention in Alzheimer's disease: characterizing cognitive subgroups of patients. Neuropsychologia 27:325-339.

Freedman M, Oscar-Berman M (1986) Selective delayed response deficits in Parkinson's and Alzheimer's disease. Arch Neurol 43:886890 .

Fuster JM (1990) Inferotemporal units in selective visual attention and short-term memory. J Neurophysiol 64:681-697.

Gaffan D, Murray EA (1992) Monkeys (Macaca fascicularis) with rhinal cortcx ablations succed in object discrimination learning dcspite 24-hr intertrial intervals and fail at matching to sample despite double sample presentations. Behav Neurosci 106:30-38.

George PJ, Horel JA, Cirillo RA (1989) Reversible cold lesions of the parahippocampal gyrus in monkeys result in deficits on the delayed match-to-sample and other visual tasks. Behav Brain Res 34:163178 .

Givens BS, Olton DS (1990) Cholinergic and GABAergic modulation of medial septal area: effect on working memory. Behav Neurosci 104:849-855.

Goldman PS, Rosvold HE (1970) Localization of function within the dorsolateral prefrontal cortex of the rhesus monkey. Exp Neurol 27: 291-304.

Gottfries CG (1990) Neurochemical aspects of dementia disorders. Dementia 1:56-64.

Grady CL, Grimes AM, Patronas N, Sunderland T, Foster NL, Rapoport SI (1989) Divided attention, as measured by dichotic speech performance in dermentia of the Alzheimer type. Arch Neurol 46:317320 .

Greenamyre JT, Young AB (1989) Excitatory amino acids and Alzheimer's disease. Neurobiol Aging 10:593-602.

Hagan JJ, Morris RGM (1988) The cholinergic hypothesis of memory: a review of animal experiments. In: Handbook of Psychopharmacology, Vol 20, Psychopharmacology of the aging nervous system (Iversen LL, Iversen SD, Snyder SH, eds), pp 237-323. New York: Plenum.

Haxby JV, Parasuraman R, Gillette J, Raffaele K (1991) Selective and divided attention to visual features are impaired in patients with early dementia of the Alzheimer type. Soc Neurosci Abstr 17:696.

Hedreen JC, Struble RG, Bacon SJ, Price DL (1983) A new histochemical technique for acetylcholinesterase (AChE) in axons. J Neuropathol Exp Neurol 42:325.

Heilman KM, Valenstein E (1985) Clinical neuropsychology, 2d ed. New York: Oxford UP.

Henke H, Lang W (1983) Cholinergic enzymes in neocortex, hippocampus and basal forebrain of non-neurological and senile dementia of Alzheimer-type patients. Brain Res 267:281-291.

Herrera-Marschitz M, Goiny M, Utsumi H, Ferre S, Håkansson L, Nordberg A, Ungerstedt U (1990) Effect of unilateral nucleus basalis lesion on cortical and striatal acetylcholine and dopamine release monitored in vivo with microdialysis. Neurosci Lett 1 10:172-179.

Horel JA, Voytko ML, Salsbury KG (1984) Visual learning suppressed by cooling the temporal pole. Behav Neurosci 98:310-324.

Horel JA, Pytko-Joiner DE, Voytko ML, Salsbury K (1987) The per- formance of visual tasks while segments of the inferotemporal cortex are suppressed by cold. Behav Brain Res 23:29-42.

Iraizoz I, de Lacalle S, Gonzalo LM (1991) Cell loss and nuclear hypertrophy in topographical subdivisions of the nucleus basalis of Meynert in Alzheimer's disease. Neuroscience 41:33-40.

Irle E, Markowitsch HJ (1987) Basal forebrain-lesioned monkeys are severely impaired in tasks of association and recognition memory. Ann Neurol 22:735-743.

Irle E, Kessler J, Markowitsch HJ, Hofmann W (1987) Primate learning tasks reveal strong impairments in patients with presenile or senile dementia of the Alzheimer type. Brain Cogn 6:429-449.

Karnovsky MJ, Roots L (1964) A "direct-coloring" thiocholine method for cholinesterase. J Histochem Cytochem 12:219-221.

Kemper T (1984) Neuroanatomical and neuropathological changes in normal aging and in dementia. In: Clinical neurology of aging (Albert ML, ed), pp 9-52. New York: Oxford UP.

Kesner RP (1988) Reevaluation of the contribution of the basal forebrain cholinergic system to memory. Neurobiol Aging 9:609-616.

Kesner RP, Johnson DL (1991) An analysis of the basal forebrain contribution to learning and memory. In: Activation to acquisition. Functional aspects of the basal forebrain cholinergic system (Richardson RT, ed), pp 263-288. Boston: Birkhäuser.

Kish SJ, El-Awar M, Schut L, Leach L, Oscar-Berman M, Freedman M (1988) Cognitive deficits in olivopontocerebellar atrophy: implications for the cholinergic hypothesis of Alzheimer's dementia. Ann Neurol 24:200-206.

Kish SJ, Robitaille Y, El-Awar M, Deck JHN, Simmons J, Schut L, Chang L-J, DiStefano L, Freedman M (1989) Non-Alzheimer-type pattern of brain cholineacetyltransferase reduction in dominantly inherited olivopontocerebellar atrophy. Ann Neurol 26:362-367.

Kitt CA, Mitchell SJ, DeLong MR, Wainer BH, Price DL (1987) Fiber pathways of basal forcbrain cholincrgic neurons in monkeys. Brain Res 406:192-206.

Koshimura K, Kato T, Tohyama I, Nakamura S, Kameyama M (1986) Qualitative abnormalities of choline acetyltransferase in Alzheimer type dementia. J Neurol Sci 76:143-150.

Mahut H (1971) Spatial and object reversal learning in monkeys with partial temporal lobe ablations. Neuropsychologia 9:409-424.

Mann DMA, Yates PO, Marcyniuk B (1984) Alzheimer's presenile dementia, senile dementia of Alzheimer type and Down's syndrome in middle age form an age related continuum of pathological changes. Neuropathol Appl Neurobiol 10:185-207.

Marcyniuk B, Mann DMA, Yates PO (1989) The topography of nerve cell loss from the locus caeruleus in elderly persons. Neurobiol Aging 10:5-9.

Markowska AL, Olton DS, Murray EA, Gaffan D (1989) A comparative analysis of the role of fornix and cingulate cortex in memory: rats. Exp Brain Res 74:187-201.

Martin-Elkins CL, George P, Horel JA (1989) Retention deficits produced in monkeys with reversible cold lesions in the prestriate cortex. Behav Brain Res 32:219-230.

Mash DC, Flynn DD, Potter LT (1985) Loss of M2 muscarine receptors in the cerebral cortex in Alzheimer's disease and experimental cholinergic denervation. Science 228:1115-1117.

Mesulam M-M (1983) The functional anatomy and hemispheric specialization for directed attention. The role of the parietal lobe and its connectivity. Trends Neurosci 6:384-387.

Mesulam M-M, Geula C (1988) Nucleus basalis (Ch4) and cortical cholinergic innervation in the human brain: observations based on the distribution of acetylcholinesterase and choline acetyltransferase. J Comp Neurol 275:216-240.

Mesulam M-M, Mufson EJ, Levey AI, Wainer BH (1983) Cholinergic innervation of cortex by the basal forebrain: cytochemistry and cortical connections of the septal area, diagonal band nuclei, nucleus basalis (substantia innominata), and hypothalamus in the rhesus monkey. J Comp Neurol 214:170-197.

Mishkin M (1982) A memory system in the monkey. Philos Trans R Soc Lond [Biol] 298:85-95.

Mueller PM, Tipper SP, Baylis GC (1991) The effect of normal aging and Alzheimer's disease on spatial attention. Soc Neurosci Abstr 17: 696.

Mufson EJ, Kordower JH (1989) Nerve growth factor receptor expressing human basal forebrain neurons: pathologic alterations in Alzheimer's and Parkinson's disease. In: Progress in clinical and biological research, Vol 317, Proceedings of the first international con- 
ference on Alzheimer's disease and related disorders (Iqbal K, Wisniewski HM, Winblad B, eds), pp 401-414. New York: Liss.

Muir JL, Dunnett SB, Robbins TW, Everitt BJ (1992) Attentional functions of the forebrain cholinergic systems: effects of intraventricular hemicholinium, physostigmine, basal forebrain lesions and intracortical grafts on a multiple-choice serial reaction time task. Exp Brain Res 89:611-622.

Murray EA, Davidson M, Gaffan D, Olton DS, Suomi S (1989) Effects of fornix transection and cingulate cortical ablation on spatial memory in rhesus monkeys. Exp Brain Res 74:173-186.

Nagai T, McGeer PL, Peng JH, McGeer EG, Dolman CE (1983) Choline acetyltransferase immunohistochemistry in brains of Alzheimer's disease patients and controls. Neurosci Lett 36:195-199.

Nilsson OG, Strecker RE, Daszuta A, Björklund A (1988) Combined cholinergic and serotonergic denervation of the forebrain produces severe deficits in a spatial learning task in the rat. Brain Res 453:235246.

Olton DS (1991) Experimental strategies to identify the neurobiological bases of memory: lesions. In: Learning and memory. A biological view, 2d ed (Martinez JL, Kesner RP, eds), pp 441-466. New York: Academic.

Olton DS, Pang K (1992) Interactions of neurotransmitters and neuroanatomy: it's not what you do, it's the place that you do it. In: Neurotransmitter interactions and cognitive function (Levin ED, Decker MW, Butcher LL, eds), pp 277-286. Boston: Birkhäuser.

Olton DS, Wenk GL (1987) Dementia: animal models of the cognitive impairments produced by degeneration of the basal forebrain cholinergic system. In: Psychopharmacology: the third generation of progress (Meltzer HY, ed), pp 941-953. New York: Raven.

Olton DS, Wenk GL, Church RM, Meck WH (1988) Attention and the frontal cortex as examined by simultaneous temporal processing. Neuropsychologia 26:307-318.

Olton D, Markowska A, Voytko ML, Givens B, Gorman L, Wenk G (1991a) Basal forebrain cholinergic system: a functional analysis. In: The basal forebrain: anatomy to function (Napier TC, Kalivas PW, Hanin I, eds), pp 353-372. New York: Plenum.

Olton DS, Wenk GL, Markowska AM (1991b) Basal forebrain, memory and attention. In: Activation to acquisition. Functional aspects of the basal forebrain cholinergic system (Richardson RT, ed), pp 247-262. Boston: Birkhäuser.

Olton DS, Givens BS, Markowska AL, Shapiro M, Golski S (1991c) Mnemonic functions of the cholinergic septohippocampal system. In: Memory: organization and locus of change (Squirc LR, ed), pp 250269. New York: Oxford UP.

Palmer AM, Procter AW, Stratmann GC, Bowen DM (1986) Excitatory amino acid-releasing and cholinergic neurones in Alzheimer's disease. Neurosci Lett 66:199-204.

Palmer AM, Wilcock GK, Esiri MM, Francis PT, Bowen DM (1987) Monoaminergic innervation of the frontal and temporal lobes in $\mathrm{Al}$ zheimer's disease. Brain Res 401:231-238.

Pang K, Williams MJ, Egeth H, Olton DS (1993) Nucleus basalis magnocellularis (NBM) and attention: effects of muscimol infusions. Behav Neurosci, in press.

Parasuraman R, Greenwood PM, Haxby JV, Grady CL (1992) Visuospatial attention in dementia of the Alzheimer type. Brain 115: $711-733$

Pascual J, Fontán A, Zarranz JJ, Berciano J, Flórez J, Pazos A (1991) High-affinity choline uptake carrier in Alzheimer's disease: implications for the cholinergic hypothesis of dementia. Brain Res 552:170 174.

Penetar DM, McDonough JH (1983) Effects of cholinergic drugs on delayed match-to-sample performance of rhesus monkeys. Pharmacol Biochem Behav 19:963-967.

Perry EK, Perry RH, Smith CJ, Purohit D, Bonham J, Dick DJ, Candy JM, Edwardson JA, Fairbairn A (1986) Cholinergic receptors in cognitive disorders. Can J Neurol Sci 13:521-527.

Perry RH, Candy JM, Perry EK, Irving D, Blessed G, Fairbairn AF, Tomlinson BE (1982) Extensive loss of choline acetyltransferase activity is not reflected by neuronal loss in the nucleus of Meynert in Alzheimer's disease. Neurosci Lett 33:311-315.

Petersen SE, Robinson DL (1986) Damage to parietal cortex produces a similar deficit in man and monkey. Invest Ophthalmol Vis Sci 27[Suppl 3]:18.

Petersen SE, Robinson DL, Currie JN (1989) Influences of lesions of parietal cortex on visual spatial attention in humans. Exp Brain Res 76:267-280.

Petersen SE, Corbetta M, Shulman GL, Miezin FM (1991) Frontal activation during shifts of visual spatial attention: a pet study. Soc Neurosci Abstr 17:1210.

Phillips RR, Malamut BL, Bachevalier J, Mishkin M (1988) Dissociation of the effects of inferior temporal and limbic lesions on object discrimination learning with 24 -h intertrial intervals. Behav Brain Res 27:99-107.

Posner MI (1980) Orienting of attention. Q J Exp Psychol 32:3-25.

Posner MI, Cohen Y (1984) Components of visual orienting. In: Attention and performance. X. Control of language processes (Bouma H, Bouwhuis DG, eds), pp 531-556. London: Erlbaum.

Posner MI, Cohen Y, Rafal RD (1982) Neural systems control of spatial orienting. Philos Trans R Soc Lond [Biol] 298:187-198.

Posner MI, Walker JA, Friedrich FA, Rafal RD (1984) Effects of parietal injury on covert orienting of attention. J Neurosci 4:18631874.

Posner MI, Walker JA, Friedrich FA, Rafal RD (1987) How do the parietal lobes direct covert attention? Neuropsychologia 25:135-145.

Price DL, Whitehouse PJ, Struble RG, Clark AW, Coyle JT, DeLong MR, Hedreen JC (1982) Basal forebrain cholinergic systems in Alzheimer's disease and related dementias. Neurosci Comment 1:84-92.

Price JL, Davis PB, Morris JC, White DL (1991) The distribution of tangles, plaques and related immunohistochemical markers in healthy aging and Alzheimer's disease. Neurobiol Aging 12:295-312.

Quirion R, Martel JC, Robitaille Y, Etienne P, Wood P, Nair NPV, Gauthier S (1986) Neurotransmitter and receptor deficits in senile dementia of the Alzheimer type. Can J Neurol Sci 13:503-510.

Raffaele KC, Olton DS (1988) Hippocampal and amygdaloid involvement in working memory for nonspatial stimuli. Behav Neurosci 102: 349-355.

Richardson RT, DeLong MR (1991) Functional implications of tonic and phasic activity changes in nucleus basalis neurons. In: Activation to acquisition. Functional aspects of the basal forebrain cholinergic system (Richardson RT, ed), pp 135-166. Boston: Birkhäuser.

Richter-Levin G, Segal M (1989) Spatial performance is severely impaired in rats with combined reduction of serotonergic and cholinergic transmission. Brain Res 477:404-407.

Ridley RM, Bowes PM, Baker HF, Crow TJ (1984) An involvement of acetylcholine in object discrimination learning and memory in the marmoset. Neuropsychologia 22:253-263.

Ridley RM, Baker HF, Drewett B, Johnson JA (1985) Effects of ibotenic acid lesions of the basal forebrain on serial reversal learning in marmosets. Psychopharmacology 86:438-443.

Ridley RM, Murray TK, Johnson JA, Baker HF (1986) Learning impairment following lesion of the basal nucleus of Meynert in the marmoset: modification by cholinergic drugs. Brain Res 376:108116.

Ridley RM, Baker HF, Murray TK (1988a) Basal nucleus lesions in monkeys: recognition memory impairment or visual agnosia? Psychopharmacology 95:289-290.

Ridley RM, Samson NA, Baker HF, Johnson JA (1988b) Visuospatial learning impairment following lesion of the cholinergic projection to the hippocampus. Brain Res 456:71-87.

Ridley RM, Aitken DM, Baker HF (1989) Learning about rules but not about reward is impaired following lesions of the cholinergic projection to the hippocampus. Brain Res 502:306-318.

Riekkinen M, Riekkinen P, Riekkinen P (1991) Comparison of quisqualic and ibotenic acid nucleus basalis magnocellularis lesions on water-maze and passive avoidance performance. Brain Res Bull 27: 119-123.

Riekkinen P, Sirviö J, Riekkinen P (1990) Interaction between raphe dorsalis and nucleus basalis magnocellularis in spatial learning. Brain Res 527:342-345.

Rinne JO, Paljärvi L, Rinne UK (1987) Neuronal size and density in the nucleus basalis of Meynert in Alzheimer's disease. J Neurol Sci 79:67-76.

Robbins TW, Everitt BJ; Marston HM, Wilkinson J, Jones GH, Page KJ (1989) Comparative effects of ibotenic acid- and quisqualic acidinduced lesions of the substantia innominata on attentional function in the rat: further implications for the role of the cholinergic neurons of the nucleus basalis in cognitive processes. Behav Brain Res 35: 221-240.

Roberts AC, Robbins TW, Everitt BJ, Jones GH, Sirkia TE, Wilkinson 
J, Page K (1990) The effects of excitotoxic lesions of the basal forebrain on the acquisition, retention and serial reversal of visual discriminations in marmosets. Neuroscience 34:311-329.

Roberts AC, Robbins TW, Everitt BJ, Muir JL (1992) A specific form of cognitive rigidity following excitotoxic lesions of the basal forebrain in marmosets. Neuroscience 47:251-264.

Robinson DL, Bowman EM, Kertzman C (1991) Covert orienting of attention in macaque. II. A signal in parietal cortex to disengage attention. Soc Neurosci Abstr 17:442.

Rossor M, Iversen LL (1986) Non-cholinergic neurotransmitter abnormalities in Alzheimer's disease. Br Med Bull 42:70-74.

Rossor MN, Garrett NJ, Johnson AL, Mountjoy CQ, Roth M, Iversen LL (1982) A post-mortem study of the cholinergic and GABA systems in senile dementia. Brain 105:313-330.

Rupniak NMJ, Steventon MJ, Ficld MJ, Jennings CA, Iversen SD (1989) Comparison of the effects of four cholinomimetic agents on cognition in primates following disruption by scopolamine or by lists of objects. Psychopharmacology 99:189-195.

Rye DB, Wainer BH, Mesulam M-M, Mufson EJ, Saper CB (1984) Cortical projections arising from the basal forebrain: a study of cholinergic and noncholinergic components employing combined retrograde tracing and immunohistochemical localization of choline acetyltransferase. Neuroscience 13:627-643.

Sahakian BJ (1988) Cholinergic drugs and human cognitive performance. In: Handbook of psychopharmacology, Vol 20, Psychopharmacology of the aging nervous system (Iversen LL, Iversen SD, Snyder SH, eds), pp 393-424. New York: Plenum.

Sahakian BJ, Morris RG, Evenden JL, Heald A, Levy R, Philpot M, Robbins TW (1988) A comparative study of visuospatial memory and learning in Alzheimer-type dementia and Parkinson's disease. Brain 111:695-718.

Sahakian B, Jones G, Levy R, Gray J, Warburton D (1989) The effects of nicotine on attention, information processing, and short-term memory in patients with dementia of the Alzheimer type. Br J Psychiatry 154:797-800.

Saper CB, German DC, White CL (1985) Neuronal pathology in the nucleus basalis and associated cell groups in senile dementia of the Alzheimer's type: possible role in cell loss. Neurology 35:1089-1095.

Sato $T$ (1988) Effects of attention and stimulus interaction on visual responses of inferior temporal neurons in macaque. J Neurophysiol 60:344-364.

Saunders RC, Aigner TG, Frank JA (1990) Magnetic resonance imaging of the rhesus monkey brain: use for stereotactic neurosurgery. Exp Brain Res 81:443-446.

Scheff SW, DeKosky ST, Price DA (1990) Quantitative assessment of cortical synaptic density in Alzheimer's disease. Neurobiol Aging 11: 29-37.

Semba K (1991) The cholinergic basal forebrain: a critical role in cortical arousal. In: The basal forebrain. Anatomy to function (Napier TC, Kalivas PW, Hanin I, eds), pp 197-217. New York: Plenum.

Sillito AM, Murphy PC (1987) The cholinergic modulation of cortical function. In: Cerebral cortex, Vol 6, Further aspects of cortical functions including hippocampus (Jones EG, Peters A, eds), pp 161-185. New York: Plenum.

Singer W (1979) Central-core control of visual-cortex functions. In: The neurosciences. Fourth study program (Schmitt FO, Worden FG, eds), pp 1093-1110. Cambridge, MA: MIT Press.

Spencer DG, Lal H (1983) Effects of anticholinergic drugs on learning and memory. Drug Dev Res 3:489-502.

Spinnler II (1991) The role of attention disorders in the cognitive deficits of dementia. In: Handbook of neuropsychology, Vol 5 (Boller F, Grafman J, eds) pp 79-122. Amsterdam: Elsevier.

Snitzer H, Desimone R, Moran J (1988) Increased attention enhances both behavioral and neuronal performance. Science 240:338-340.

Squire LR, Zola-Morgan S (1991) The medial temporal lobe memory system. Science 253:1380-1386.

Struble RG, Lehmann J, Mitchell SJ, McKinney M, Price DL, Coyle
JT, DeLong MR (1986) Basal forebrain neurons provide major cholinergic innervation of primate neocortex. Neurosci Lett 66:215220.

Stuss DT, Benson DF (1986) The frontal lobes. New York: Raven.

Sunderland T, Tariot PN, Mueller EA, Murphy DL, Weingartner H, Cohen RM (1985a) Cognitive and behavioral sensitivity to scopolamine in Alzheimer patients and controls. Psychopharmacol Bull 21:676-679.

Sunderland T, Tariot PN, Murphy DL, Weingartner H, Mueller EA, Cohen RM (1985b) Scopolamine challenges in Alzheimer's disease. Psychopharmacology 87:247-249.

Tagliavini F, Pilleri G (1983) Basal nucleus of Meynert. A neuropathological study in Alzheimer's disease, simple senile dementia, Pick's disease and Huntington's chorea. J Neurol Sci 62:243-260.

Tagliavini F, Pilleri G, Bouras C, Constantinidis J (1984) The basal nucleus of Meynert in idiopathic Parkinson's disease. Acta Neurol Scand 69:20-28.

Tsuji S (1974) On the chemical basis of thiocholine methods for demonstration of acetylcholinesterase activities. Histochemistry 42:99110.

Vanderwolf $\mathrm{CH}$ (1987) Near-total loss of "learning" and "memory" as a result of combined cholinergic and serotonergic blockade in the rat. Behav Brain Res 23:43-57.

Vogels OJM, Broere CAJ, Ter Laak HJ, Ten Donkelaar HJ, Nieuwenhuys R, Schulte BPM (1990) Cell loss and shrinkage in the nucleus basalis Meynert complex in Alzheimer's disease. Neurobiol Aging 11: $3-13$.

Voytko ML (1985) Cooling orbital frontal cortex disrupts matchingto-sample and visual discrimination learning in monkcys. Physiol Psychol 13:219-229.

Voytko ML (1986) Visual learning and retention examined with reversible cold lesions of the anterior temporal lobe. Behav Brain Res 22:25-39.

Voytko ML, Kitt CA, Price DL (1992) Cholinergic immunoreactive fibers in monkey anterior temporal cortex. Cereb Cortex 2:48-55.

Wenk GL, Harrington CA, Tucker DA, Rance NE, Walker LC (1992) Basal forebrain neurons and memory: a biochemical, histological, and behavioral study of differential vulnerability to ibotenate and quisqualate. Behav Neurosci 106:909-923.

Wesnes K, Warburton DM (1983) Effects of scopolamine on stimulus sensitivity and response bias in a visual vigilance task. Neuropsychobiology 9:154-157.

Whitehouse PJ, Price DL, Struble RG, Clark AW, Coyle JT, DeLong MR (1982) Alzheimer's disease and senile dementia: loss of neurons in the basal forebrain. Science 215:1237-1239.

Wilcock GK, Esiri MM, Bowen DM, Smith CCT (1982) Alzheimer's disease. Correlation of cortical choline acetyltransferase activity with the severity of dementia and histological abnormalities. J Neurol Sci $57: 407-417$.

Wilcock GK, Esiri MM, Bowen DM, Hughes AO (1988) The differential involvement of subcortical nuclei in senile dementia of Alzheimer's type. J Neurol Neurosurg Psychiatry 51:842-849.

Yamamoto T, Hirano A (1985) Nucleus raphe dorsalis in Alzheimer's disease: neurofibrillary tangles and loss of large neurons. Ann Neurol 17:573-577.

Zola-Morgan S, Squire LR (1986) Memory impairment in monkeys following lesions limited to the hippocampus. Behav Neurosci 100: 155-160.

Zola-Morgan S, Squire LR, Amaral DG (1989a) Lesions of the hippocampal formation but not lesions of the fornix or the mammillary nuclei produce long-lasting memory impairment in monkeys. J Neurosci 9:898-913.

Zola-Morgan S, Squire LR, Amaral DG, Suzuki WA (1989b) Lesions of perirhinal and parahippocampal cortex that spare the amygdala and hippocampal formation produce severe memory impairment. J Neurosci 9:4355-4370. 